\title{
THE PRODUCT REFORMULATION JOURNEY SO FAR: AN ASSESSMENT
}

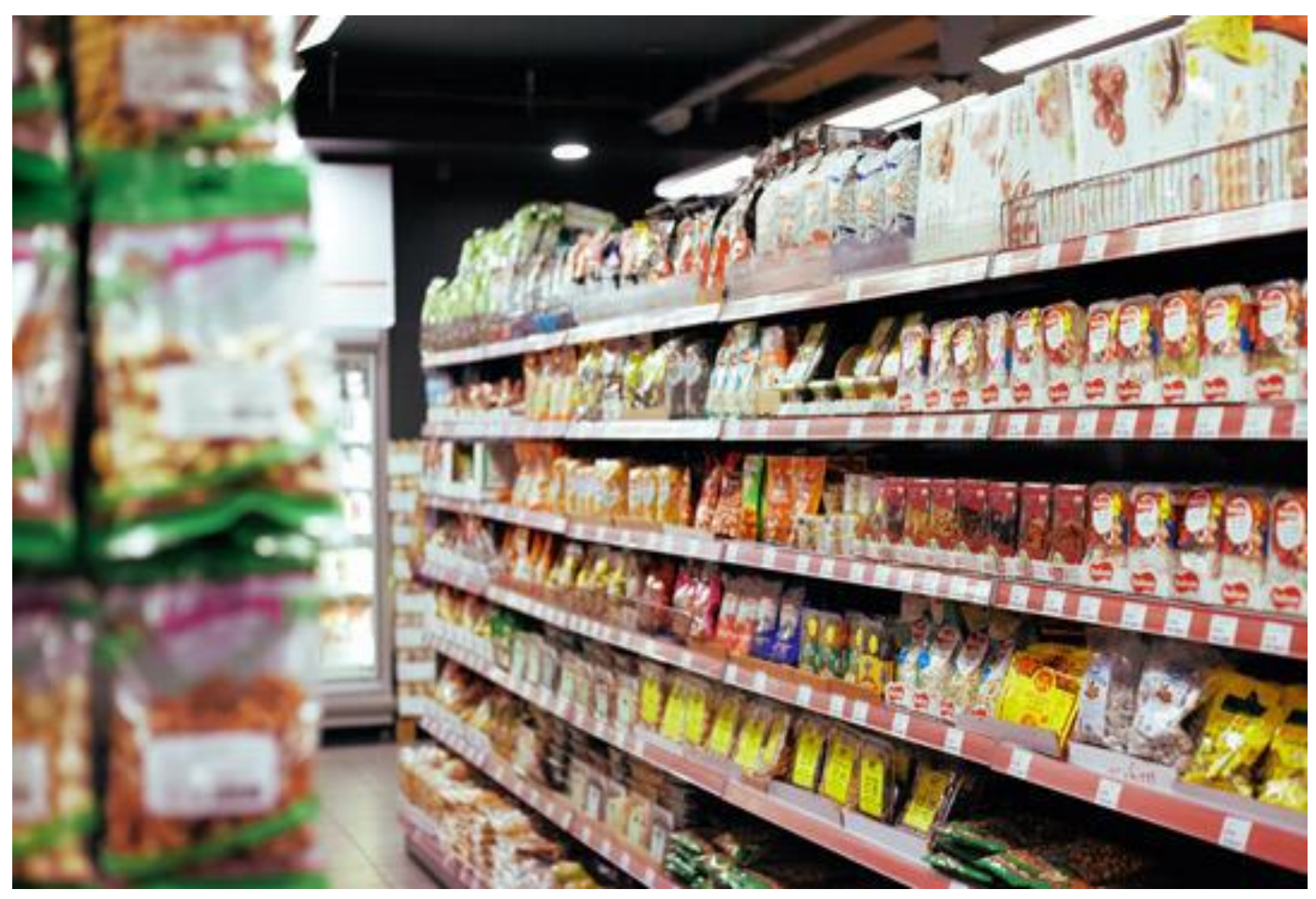

GAIN Discussion Paper $n^{\circ} 8$

October, 2020

Jessica Fanzo and Rebecca McLaren 


\section{ABOUT GAIN}

The Global Alliance for Improved Nutrition (GAIN) is a Swiss-based foundation launched at the UN in 2002 to tackle the human suffering caused by malnutrition. Working with governments, businesses and civil society, we aim to transform food systems so that they deliver more nutritious food for all people, especially the most vulnerable.

\section{Recommended citation}

Fanzo J, and McLaren R. The Product Reformulation Journey So Far: An Assessment. Global Alliance for Improved Nutrition (GAIN). Discussion Paper \#8. Geneva, Switzerland, 2020. DOI:

https://doi.org/10.36072/dp.8

\section{(C) The Global Alliance for Improved Nutrition (GAIN)}

This work is available under the Creative Commons Attribution-Non-Commercial-Share Alike 4.0 IGO licence (CC BY-NC-SA 4.0 IGO; https://creativecommons.org/licenses/by-nc-sa/4.0/). Under the terms of this licence, you may copy, redistribute, and adapt the work for non-commercial purposes, provided the work is appropriately cited, as indicated below. In any use of this work, there should be no suggestion that GAIN endorses any specific organisation, products or services. The use of the GAIN logo is not permitted. If you adapt the work, then you must license your work under the same or equivalent Creative Commons license. The contributions of third parties do not necessarily represent the view or opinion of GAIN.

\section{Acknowledgements}

The authors are affiliated with Johns Hopkins University. All photographs included in this document have been taken with consent for use in publications. The authors wish to thank Norah Campbell, Courtney Scott, Boyd Swinburn, Francesco Branca, Lynnette Neufeld, Lawrence Haddad, and Steve Godfrey as well as the World Business Council for Sustainable Development (WBCSD) for their feedback on previous versions of this paper.

\section{GAIN DISCUSSION PAPER SERIES}

The GAIN Discussion Paper series is designed to spark discussion and debate and to inform action on topics of relevance to improving the consumption of nutritious, safe foods for all, especially the most vulnerable.

The Global Alliance for Improved Nutrition (GAIN)

Rue de Varembé 7

1202 Geneva

Switzerland

$\mathrm{T}:+41227491850$

E: info@gainhealth.org

www.gainhealth.org 


\section{SUMMARY}

A more detailed Executive Summary is available as an annex to the paper.

Deteriorating nutrition and health outcomes have stimulated nutrition programmes and policies to strive to reduce the intake of salt, added sugar, and unhealthy fats towards recommended targets. Alongside promoting the consumption of fresh nutritious foods (e.g., fruits, vegetables, and whole grains), reformulation of processed foods may make an important contribution to improving diets. Reformulation, a change to a food or beverage's processing or composition, can either reduce potentially harmful ingredients or nutrients such as salt, added sugar, saturated and trans fats, and energy density - or increase potentially beneficial ingredients or nutrients - such as micronutrients, fibre, or protein. This paper reviews the food product reformulation landscape to highlight the challenges and opportunities to increasing the effectiveness of food reformulation. We focus on reformulation for the purpose of making a positive public health contribution, examine it within both voluntary and mandatory contexts. and consider complex consumer responses.

Most reformulation has been voluntary, leading to uneven coverage; while there have been few mandatory limits, mandatory reformulation allows the public health sector to set and monitor health-based targets. There are certain supply side challenges to reformulation, including the technical difficulty of reducing or removing ingredients. On the demand side, consumer acceptance of reformulated products can be unpredictable and risky. However, there are also supply and demand opportunities to reformulate, including positive incentives and emerging consumer demands for healthier, more sustainable products. While studies have shown that reformulation could have significant public health impacts, rigorous evaluation is rare and difficult. Moreover, reformulation will not shift diets towards more minimally processed foods, such as fruits and vegetables. To do so, actions are needed to improve availability, affordability, and demand for these nutritious foods.

\section{KEY MESSAGES}

- Processed foods are likely to remain a big part of diets in the future and making them contribute more towards improving human health is critical.

- Enhancing nutritional value, increasing the nutrient density, and limiting the unhealthful components of processed foods through reformulation may have an important role to play in our future food system.

- While voluntary reformulation has worked to an extent, mandatory reformulation increases the potential benefits as it can set more ambitious and comprehensive targets that can be enforced.

- However, this must be done alongside larger scale efforts to improve dietary intakes of minimally processed foods and dietary diversity such as mandatory labelling, taxes, and subsidies. 


\section{BACKGROUND AND OBJECTIVE}

There is growing evidence of the detrimental effects of sub-optimal diets on health, including cardiovascular disease, diabetes, and some types of cancers. The deaths and disabilityadjusted life years (DALYs) attributed to poor diets, 11 million and 255 million, respectively, have surpassed those from smoking (2017 data; Afshin et al. 2019). High-risk diets are those low in fruits, vegetables, whole grains, legumes, nuts, and seeds and those high in salt, sugar, unhealthy fats, and red and processed meats (Afshin et al. 2019; Willett et al. 2019; Swinburn et al. 2019; Immamura et al. 2015).

Deteriorating nutrition and health outcomes among the global population have stimulated national and international nutrition programmes and policies to strive to reduce micronutrient deficiencies as well as reduce the intake of salt, added sugar, and unhealthy fats to the targets recommended by national governments and the World Health Organization (WHO). One strategy, among many, is to reformulate foods to create healthier alternatives.

Reformulation is defined as the process of altering a food or beverage product's processing or composition to improve the product's health profile or to reduce the content of harmful ingredients or nutrients (Scott et al. 2017). This differs from the creation of new food products, although this is also important in improving diets. Reformulation often relies on nutrient profiling, or the process of classifying or ranking foods based on their nutrient composition, such as the amount of salt, added sugar, and saturated and trans fats and by adding positive nutrients or components such as whole grains, fibre, or micronutrients (Drewnowski 2017; WHO 2010). Typical examples of reformulation include reducing salt, added sugars, saturated and trans fats, or dietary energy density (also known as reducing negative nutrients, harmful nutrients, or nutrients to limit). Other examples include increasing dietary fibre or protein, also known as adding beneficial nutrients. Fortification is defined as the process of adding micronutrients to foods or beverages, while functionalisation is defined as adding other beneficial ingredients to a food or beverage that are specifically targeted to improve health. While fortification and functionalisation are similar to reformulation in that they focus on modifying existing food products, they differ slightly and will only be discussed briefly in this paper.

The WHO's Global Non-communicable Disease (NCD) Action Plan 2013-2020 set the goal of reducing premature mortality from NCDs by $25 \%$ by 2025 . Reformulation is critical in achieving this, including reducing salt intake by $30 \%$. The WHO recommends limiting salt intake to $5 \mathrm{~g} /$ day, added sugar intake to $10 \%$ of total energy with even greater benefits at $5 \%$, and total fat intake to $30 \%$ of total energy. Fat intake should eliminate industrial trans fats and move away from saturated fat (WHO 2014). For many years, food and beverage companies have been voluntarily reformulating food products to align with national and WHO dietary and health recommendations.

The WHO called for private-sector involvement in controlling and preventing NCDs at their High-Level Meeting of the United Nations General Assembly on the Prevention and Control of Noncommunicable Diseases in 2011, in the Political Declaration of the High-Level Meeting of the General Assembly on the Prevention and Control of Non-Communicable Disease in 2012, and at the Second International Conference on Nutrition (ICN2) in 2014. Reformulation 
was identified in each case as an essential component of the effort to reduce salt, sugar, and saturated and trans fats, with an additional focus on the importance of ensuring that reformulated foods are affordable and accessible for all (WHO 2014; WHO 2012).

The WHO has periodically evaluated the progress made on reformulation and has found it to be lacking in evaluations in 2014 and 2017, especially in the affordability and accessibility of reformulated food products (WHO 2018a). Currently, the WHO is working on setting up an accountability consortium between the WHO, Access to Nutrition Foundation, George Institute, and Auckland University that will track a range of issues associated with addressing public health concerns with regard to diets, including reformulation.

There has also been increased attention on the health impacts of highly processed foods. While there is no precise definition or agreed upon criteria, highly processed foods are generally those that are made from highly processed, industrialised ingredients not found in home or restaurant kitchens and that are designed to be hyper-palatable, often conveniently ready-to-eat, shelf-stable, transportable, and, ultimately, highly profitable (Lawrence and Baker 2019; Scrinis and Montero 2018). Another term, ultra-processed foods, also does not have a clear definition or criteria but is often associated with the NOVA food classification system, and both are discussed in more detail later. Highly processed foods account for more than half of the energy consumed in many high-income countries and between one-fifth and one-third of the energy consumed in many middle-income countries, with this growing by up to $10 \%$ per year (Monteiro et al. 2019). While some have argued that there can be healthy, nutrient-dense foods at all levels of processing (Jones 2018; Gibney et al. 2017) and that processed foods are key for food and nutrition security (Augustin et al. 2016), there is an abundance of evidence that highly processed foods are high in salt, added sugar, saturated and trans fats, and energy density and low in fibre, protein, and micronutrients, contributing to overweight, obesity, and NCDs. Increasing consumption of highly processed foods has been linked with poor diets that exceed recommended limits of these harmful ingredients and contribute to overweight, obesity, and NCDs (Monteiro et al. 2019; Fardet 2018; Steele et al 2016; Poti et al. 2015; Baker and Friel 2014; Martins et al. 2013; Moubarac et al. 2012; Monteiro et al. 2011). It has been estimated that replacing half the highly processed foods consumed in the United Kingdom with minimally processed ones would result in 14,235 fewer coronary deaths and 7,820 fewer stroke deaths by 2030 (Moreira et al. 2015).

The primary objective of this review is to survey the food product reformulation landscape and highlight the challenges to and opportunities for increasing the effectiveness of food reformulation for nutrition. Many of the foods that undergo reformulation are processed foods in varying degrees. In this report, we will use existing literature as well as stakeholder interviews to discuss common examples of reformulation, determine the intents and purposes of reformulation, how and why it is done (including the negative and positive incentives for the food industry), its public health impact, the challenges and opportunities of reformulation, and, finally, recommendations for moving forward.

The report serves as an input to the 2020 Tokyo Nutrition Summit working group on "building food systems that promote healthy diets and nutrition, ensure livelihoods of producers, and are climate-smart" (N4G 2020). 


\section{METHODOLOGY}

This paper is based on a literature review and a series of key stakeholder interviews. The literature review consisted of literature searches in PubMed and Google Scholar with the following keywords: reformulation, reformulation and public health, reformulation and sodium, reformulation and salt, reformulation and sugar, reformulation and fat, reformulation and trans fats, reformulation and fibre, and alter food.

Studies were considered eligible if they addressed voluntary or mandatory food reformulation strategies aimed at reducing salt, added sugar, saturated and trans fats, energy density, or artificial ingredients or increasing the content of beneficial nutrients such as fibre, protein, unsaturated and omega-3 fats, whole grains, fruits, and vegetables in processed food products. The areas of functional foods or ingredients (i.e., superfoods) or healthy food components (e.g., adding nuts) were not included.

As a result, 101 papers were found to be relevant and included in this paper. One significant limitation of the review is that most of the papers included are from research in high-income countries-a reflection of the focus of the existing literature on this topic. More work needs to be done in low- and middle-income countries to make the research on reformulation more inclusive.

Twenty semi-structured interviews were also conducted with those in the public health sector who engage with issues around reformulation, academics who have studied reformulation, and food and beverage industry employees who work on strategic and technical aspects of reformulation. Information and quotes from the interviews are identified as being from the public health, academic, or industry sectors.

\section{FINDINGS}

\section{TYPICAL TYPES OF FOODS UNDERGOING REFORMULATION}

Reformulation is defined as the process of altering a food or beverage product's processing or composition to improve the product's health profile or to reduce the content of harmful nutrients or ingredients (Scott et al. 2017). Reformulation encompasses both removing negative ingredients and nutrients as well as adding positive ones to foods, ranging from minimally to highly processed (Table 1). While this paper will touch on many of these areas, it will focus on the removal of negative ingredients and nutrients from highly processed foods.

Table 1: Types of Reformulation by Type of Food Processing

\begin{tabular}{|l|l|l|l|l|}
\hline & $\begin{array}{c}\text { Unprocessed } \\
\text { foods }\end{array}$ & $\begin{array}{c}\text { Minimally or } \\
\text { moderately processed } \\
\text { foods }\end{array}$ & \multicolumn{2}{|c|}{ Highly processed foods } \\
\hline Example foods & $\begin{array}{l}\text { Vegetables, } \\
\text { fruits, eggs }\end{array}$ & $\begin{array}{l}\text { Dried vegetables and } \\
\text { fruits, grains, dairy } \\
\text { products, seafood }\end{array}$ & $\begin{array}{l}\text { Breads, breakfast } \\
\text { cereals, dairy } \\
\text { products }\end{array}$ & $\begin{array}{l}\text { Sugar-sweetened } \\
\text { beverages, chips, }\end{array}$ \\
\hline
\end{tabular}




\begin{tabular}{|l|l|l|l|l|}
\hline & & & & $\begin{array}{l}\text { crackers, cookies, cakes, } \\
\text { confectionary }\end{array}$ \\
\hline $\begin{array}{l}\text { Remove negative } \\
\text { ingredients and } \\
\text { nutrients }\end{array}$ & Not needed & $\begin{array}{l}\text { Lower or remove salt } \\
\text { from frozen or canned } \\
\text { vegetables and fish, } \\
\text { lower or remove added } \\
\text { sugar from dried or } \\
\text { canned fruits and dairy } \\
\text { products }\end{array}$ & $\begin{array}{l}\text { Lower or remove } \\
\text { salt, added sugar, } \\
\text { and unhealthy fats } \\
\text { from all foods in this } \\
\text { category }\end{array}$ & $\begin{array}{l}\text { Lower salt, added sugar, } \\
\text { and unhealthy fats from } \\
\text { all foods in this category, } \\
\text { but these foods should } \\
\text { still be limited in the diet; } \\
\text { beware of unhealthy } \\
\text { ingredient substitutions } \\
\text { and marketing these } \\
\text { reformulated foods as } \\
\text { 'healthy' or 'healthier' }\end{array}$ \\
\hline $\begin{array}{l}\text { Add positive } \\
\text { ingredients and } \\
\text { nutrients }\end{array}$ & Biofortification & $\begin{array}{l}\text { Biofortification, } \\
\text { fortification with } \\
\text { vitamins and minerals, } \\
\text { reformulation with } \\
\text { added fibre, protein, or } \\
\text { healthy fats }\end{array}$ & $\begin{array}{l}\text { Fortification with } \\
\text { vitamins and } \\
\text { minerals, } \\
\text { reformulation with } \\
\text { added fibre, protein, } \\
\text { or healthy fats }\end{array}$ & \begin{tabular}{l} 
Not recommended \\
\hline
\end{tabular}
\end{tabular}

Source: Adopted from HLPE 2017 Report

Reformulation focuses on processed foods. All potentially modifiable foods will be reformulated at some point for some reason. As one interview with an academic pointed out,

"You cannot reformulate an apple, you can only reformulate foods that are composite products made up of various ingredients that you can take out and put others in, so inherently they are going to be a different type of products than those that from a public health perspective we would really be pushing in dietary recommendations." (Academic Respondent)

While highly processed foods often get the most attention, minimally processed foods can be reformulated as well, such as decreasing the amount of salt in frozen or canned vegetables or added sugar in dried or canned fruit.

\section{What is processed food?}

Processed food is any food that has been modified, whether that is drying, freezing, milling, refining, hydrogenating, or other modification. Processed foods range from dried and frozen fruits and vegetables to whole grain and refined flours to sugary breakfast cereals and chips. There is a significant range in the level of processing of food, from minimally processed to highly processed, as shown in Table 2 . While dried and frozen fruits and vegetables are minimally processed, chips and sugary breakfast cereals are highly processed. 
Table 2: Classification of food and beverage products by degree of processing

\begin{tabular}{|l|l|l|}
\hline \multicolumn{1}{|c|}{ Category } & \multicolumn{1}{|c|}{ Definition } & \multicolumn{1}{c|}{ Examples } \\
\hline $\begin{array}{l}\text { Unprocessed or } \\
\text { minimally } \\
\text { processed }\end{array}$ & Single foods, no or very slight modifications & $\begin{array}{l}\text { Fresh or frozen fruits and vegetables, milk, eggs, fresh } \\
\text { fish, fresh meat }\end{array}$ \\
\hline $\begin{array}{l}\text { Basically } \\
\text { processed }\end{array}$ & $\begin{array}{l}\text { Single foods, processed as isolated food } \\
\text { components or modified by preservation } \\
\text { methods }\end{array}$ & $\begin{array}{l}\text { Sugar, oil, unsweetened canned fruit, unsalted canned } \\
\text { vegetables, white rice, flour, pasta }\end{array}$ \\
\hline $\begin{array}{l}\text { Moderately } \\
\text { processed }\end{array}$ & $\begin{array}{l}\text { Single foods with the addition of flavour } \\
\text { additives }\end{array}$ & $\begin{array}{l}\text { Sweetened canned fruit, salted canned vegetables, } \\
\text { salted nuts, whole-grain bread, cereals with no added } \\
\text { sugar }\end{array}$ \\
\hline Highly & Multi-ingredient, industrially formulated mixtures \\
processed & $\begin{array}{l}\text { Sugar-sweetened beverages, salty snacks such as } \\
\text { chips and crackers, cookies, cakes, candy, refined- } \\
\text { grain bread, ready-to-eat cereals with added sugar, } \\
\text { pre-prepared meals, margarine, ketchup, mayonnaise }\end{array}$ \\
\hline
\end{tabular}

Source: Adapted from Poti et al. (2015), Moubarac et al. (2014).

The processing of food has a role in food safety, preservation, storage, and minimisation of food loss and waste as well as taste and convenience (Gibney et al. 2017). This is key for dried, frozen, and canned fruits, vegetables, fish, and meat and pasteurised, skimmed, and fermented dairy products such as milk, butter, and yogurt. However, it is less applicable to highly processed foods. A food classification system known as NOVA (see Box 1) categorises the levels of processed foods and this relationship to nutrition and health, but it has been considered controversial by some who argue that food processing is not inherently unhealthy and that the NOVA system is vague and confusing (Box 1). 
NOVA is a food classification system that groups foods based on the amount of food processing instead of their nutrients. All foods are divided into four groups based on the methods and ingredients involved in their processing at any time between being harvested and being sold to consumers. Processing used in preparation of food at home or in restaurants is not considered. The four groups are as follows:

\section{Group 1: Unprocessed or minimally processed foods}

Unprocessed foods are those that are in the same form as when they are harvested. This includes fruits, vegetables, some seafood and meat, and eggs. Minimally processed foods are those that are close to the same form as when they are harvested but have been altered slightly through processes such as removing inedible or unwanted parts, freezing, drying, grinding, cooking, or other similar processes. Importantly, minimally processed foods do not have any added salt, sugar, or fats. This includes dried fruit, frozen vegetables, legumes, grains, and some seafood and meat. Foods that are made by combining two or more foods from this group would also be included here. Foods in this group may have nutrients added back to replace those lost during processing, such as fortified flour, as well as limited preservatives, such as vacuum packaged vegetables with antioxidants.

\section{Group 2: Processed culinary ingredients}

Processed culinary ingredients are those obtained from unprocessed or minimally processed foods (group 1) through drying, refining, pressing, or grinding. These are ingredients that are rarely consumed alone and would be found in home or restaurant kitchens, such as salt, sugar, molasses, honey, syrup, vegetable oils, butter, starches, and spices.

\section{Group 3: Processed foods}

Processed foods are those that have processed culinary ingredients (group 2) added to unprocessed or minimally processed foods (group 1). Most processed foods still have relatively few ingredients, usually three or fewer. This includes canned fruits with added sugar, canned vegetables or legumes with added salt, salted or sugared nuts, some breads, cheese, cured or smoked meats, and canned fish with added salt. Foods in this group may also have limited preservatives.

\section{Group 4: Ultra-processed food products}

Ultra-processed foods are industrial formulations with many ingredients, often five or more, including salt, sugar, fats, and preservatives as seen in processed foods (group 3) as well as ingredients not usually used in home or restaurant culinary preparation including those "directly extracted from foods, such as casein, lactose, whey, and gluten, and some derived from further processing of food constituents, such as hydrogenated or inter-esterified oils, hydrolysed proteins, soy protein isolate, maltodextrin, invert sugar, and high fructose corn syrup. Classes of additive only found in ultraprocessed products include dyes and other colours, colour stabilizers, flavours, flavour enhancers, non-sugar sweeteners, and processing aids such as carbonating, firming, bulking and anti-bulking, defoaming, anti-caking and glazing agents, emulsifiers, sequestrants, and humectants" (Monteiro et al. 2016). This includes breakfast cereals, frozen pizzas and other meals, chips, crackers, cookies, cakes, and confectionary. 


\section{BOX 1 (CONTINUED)}

The creators of this system believed that is was important to have more nuance in discussing the degree of processing than simply unprocessed or processed, as most foods are now processed to some extent. The idea behind the classification system is that "the extent and purpose of food processing had changed globally, and that these changes were driving the emergence of a harmful global food system and the pandemic of obesity and other nutrition-related chronic noncommunicable diseases" (Monteiro et al. 2016).

There are actors in the nutrition and health community who agree that ultra-processed foods are uniquely harmful for health, as discussed in reference to highly processed foods above (Monteiro et al. 2019; Scrinis and Monteiro 2018; Fardet 2018; Steele et al. 2016; Poti et al. 2015; Moubarac et al. 2012). However, others argue that there can be nutrient-dense ultra-processed foods and nutrient-poor foods with less processing and that it is more useful to look at foods based on their nutrient density (Jones 2018; Gibney et al. 2017). Additionally, they argue that the NOVA classification is too vague and confusing and does not meet the criteria - understandability, affordability, workability, and practicality - for dietary guidance (Jones 2018; Gibney et al. 2017). Jones continues that "consumers' confusion about definitions and food categorizations, inadequate cooking and meal planning skills and scarcity of resources (time, money), may impede adoption and success of NOVA" (Jones 2018).

However, highly processed foods can be high in salt, added sugar, saturated and trans fats, and energy density. These foods have other potentially problematic attributes, such as being very convenient, often ready to eat, highly palatable, and strongly marketed. Additionally, they have harmful health impacts (Monteiro et al. 2019; Fardet 2018; Steele et al 2016; Poti et al. 2015; Baker and Friel 2014; Martins et al. 2013; Moubarac et al. 2012; Monteiro et al. 2011).

\section{The role of highly processed food in diets}

Highly processed foods, such as sugar-sweetened beverages, chips, crackers, cookies, cakes, pies, pastries, and candy now comprise a significant share of many diets around the world: more than half of the energy consumed in many high-income countries and between one-fifth and one-third of the energy consumed in many middle-income countries, with this growing by up to $10 \%$ per year (Monteiro et al. 2019). The Global Nutrition Report showed that Europe, North America, and Oceania purchase the highest volumes of packaged, highly processed foods, although sales growth is stagnant or declining. In contrast, regions that are home to the bulk of the world's population - Asia and Africa - are experiencing significant growth in sales, albeit from a lower baseline. Globally, sales of total per capita volumes of packaged food rose from $67.7 \mathrm{~kg}$ per capita in 2005 to $76.9 \mathrm{~kg}$ per capita in 2017 (DI 2018). 
One interview with industry pointed out the convenience of packaged, processed foods, stating,

\footnotetext{
"You could argue we could all just eat fruits and vegetables, but people want things that they can put in kids' lunch boxes or take on the train and do not spill or leak everywhere. So, from an innovation point of view, the industry is trying to find healthier, lower calorie, satiating offerings that consumers want to buy to fit into the portfolio of snacking or main meal offerings." (Industry Respondent)
}

While the trends in sales of packaged foods are relatively clear, there is debate about how packaged, highly processed foods contribute to poor diets. These debates centre on the nutrient quality and health impacts of consuming packaged foods that are industrially processed and manufactured from multiple highly processed ingredients. For example, some studies conclude that this increases the overall dietary content of salt, added sugars, saturated and trans fats, and energy density, while decreasing dietary fibre, protein, potassium, iron, zinc, magnesium, and other micronutrients (Monteiro et al. 2018; Steele et al. 2018). Other studies point to an association between intake of packaged, highly processed foods and obesity, dyslipidemia, hypertension, gastrointestinal disorders, and some cancers, including breast cancer (Fiolet et al. 2018; Schnabel et al. 2018; Mendonca et al. 2017; Monteiro et al. 2016; Rauber et al. 2015).

In one interview with someone in the public health sector, they described their beliefs that highly processed foods are harmful for health but that there is a need for more evidence, stating, "Now is processing per se an issue? Probably, I don't have the answer, but we are going to look at the degree of processing as an independent element, independent from the actual contents of sugar, fat, and salt, [in diet patterns]." (Public Health Respondent)

New, large-scale data is helping to inform this debate by providing insights into the nutrient content of the packaged food supply. One study analysed the nutritional quality of 23,013 products sold by 21 of the world's largest food and beverage producers in Australia, China, Hong Kong, India, Mexico, New Zealand, South Africa, and the United Kingdom. The analysis included up to five of the best-selling categories for each company in each country, based on 2016 sales data from Euromonitor International. Some categories were not eligible for inclusion, such as minimally processed products that typically do not require nutrition labelling and baby food.

The nutritional quality of each product was determined by applying the Health Star Rating (HSR) system (developed and used in Australia but applicable in any market). Products are rated between 0.5 stars (least healthy) to 5 stars (most healthy), and any product that scores 3.5 or above is considered healthy. The HSR system assesses risk nutrients (salt, total sugar, saturated fat, and overall energy) and positive nutrients (fibre, protein, fruit and vegetable content, and in some cases, calcium), and scores products on the basis of nutritional composition per 100 grams or 100 millilitres. 
The proportion of packaged food products in each country that have an HSR of 3.5 or more ranged from $37 \%$ of the products assessed in New Zealand and 34\% in Australia and the United States to $31 \%$ in the United Kingdom and less than 25\% in China, India, Mexico, and South Africa. The results suggest a disparity between developed and emerging markets. On average, across all nine markets, $31 \%$ of products have an HSR of 3.5 or more, meaning $69 \%$ of products did not meet the healthy threshold and thus are of low nutritional quality.

In 2018, the Access to Nutrition Foundation also published the Global Access to Nutrition Index (ATNI), which tracks companies' policies, management systems, and disclosures on seven key nutrition topics, including improving their product portfolios, responsible labelling and marketing, and affordability and accessibility of less unhealthy packaged food products. Key findings were that many food companies have increased their efforts to contribute to better diets since the last index two years ago, as shown by an increase in the average score from 2.5 to 3.3 out of 10; however, this score is still very low. Increasingly, companies' efforts to make and market less unhealthy packaged food products are being embedded in their commercial strategies, rather than their corporate social responsibility initiatives, as was often the case in the past. Demand for products that enable healthy diets is becoming a major growth driver for businesses. However, the low average index score shows that most companies have much room to improve (ATNI 2018). See Box 2 for more details.

\section{BOX 2: ATNI RANKINGS OF REFORMULATED PRODUCTS}

The Global ATNI 2018 report examined company led reformulation (Table 3). They found that of the 22 companies assessed, most have only set product reformulation targets for half of the product categories and the targets are poorly defined. Most companies (16) define one or more targets to reformulate their products, but six companies do not report any relevant targets. Across all companies and categories, in about half of all product categories assessed (61 out of 117), companies did not set targets for relevant nutrients. None of the companies has yet to establish a full set of targets for all relevant nutrients across all product categories. The large majority of companies (19) have not yet set targets to increase positive nutrients (i.e. fruits, vegetables, nuts, legumes, and whole grains). Targets that have been set are poorly defined in many cases. For example, they are not applied to all relevant products or, in the case of relative reduction targets, baseline values and deadlines are not clear.

The ATNI report made clear recommendations:

1. Companies should work to improve the nutritional quality of their existing products, particularly established, high-sales volume products. Most companies only moderately improved their scores on product innovation and reformulation targets, on average by less than one point. Furthermore, the Product Profile outcomes show that, for the large part, companies' product portfolios do not meet the healthy standard.

2. Companies should set and publish targets for achieving clear, objective nutrition criteria, covering all products and relevant nutrients, globally. Reformulation targets should also include increasing positive nutrients for qualifying products. All companies should define targets as absolute nutritional criteria based on a weight, volume, or calorie basis, with a clear time frame of achieving it, to enable verification by independent parties. 


\section{BOX 2 (CONTINUED)}

3. Employ a Nutrient Profiling System that is applied to all products, as the basis for the company's product formulation and/or reformulation efforts and its definition of healthy products.

4. Product reformulation targets should be verified by third parties. Currently, product reformulation targets are expressed by individual companies as well as via their membership in industry associations, notably the International Food and Beverage Alliance (IFBA). The IFBA requires its members to define reformulation targets and publishes regular reports on the progress they are making to improve product compositions (Table 3). However, this is based on companies' self-reporting. The achievement of reformulation targets can only be verified by the companies themselves because of the way they are articulated, which applies to most non-IFBA companies' reformulation targets as well.

5. Companies should look to increase the proportion of healthier products within their portfolios, particularly products they market to children or that are a significant part of children's diets. This can be done by investing in making products healthier and by acquiring companies with healthy product portfolios.

Table 3: Overview of product reformulation targets evaluated by ATNI

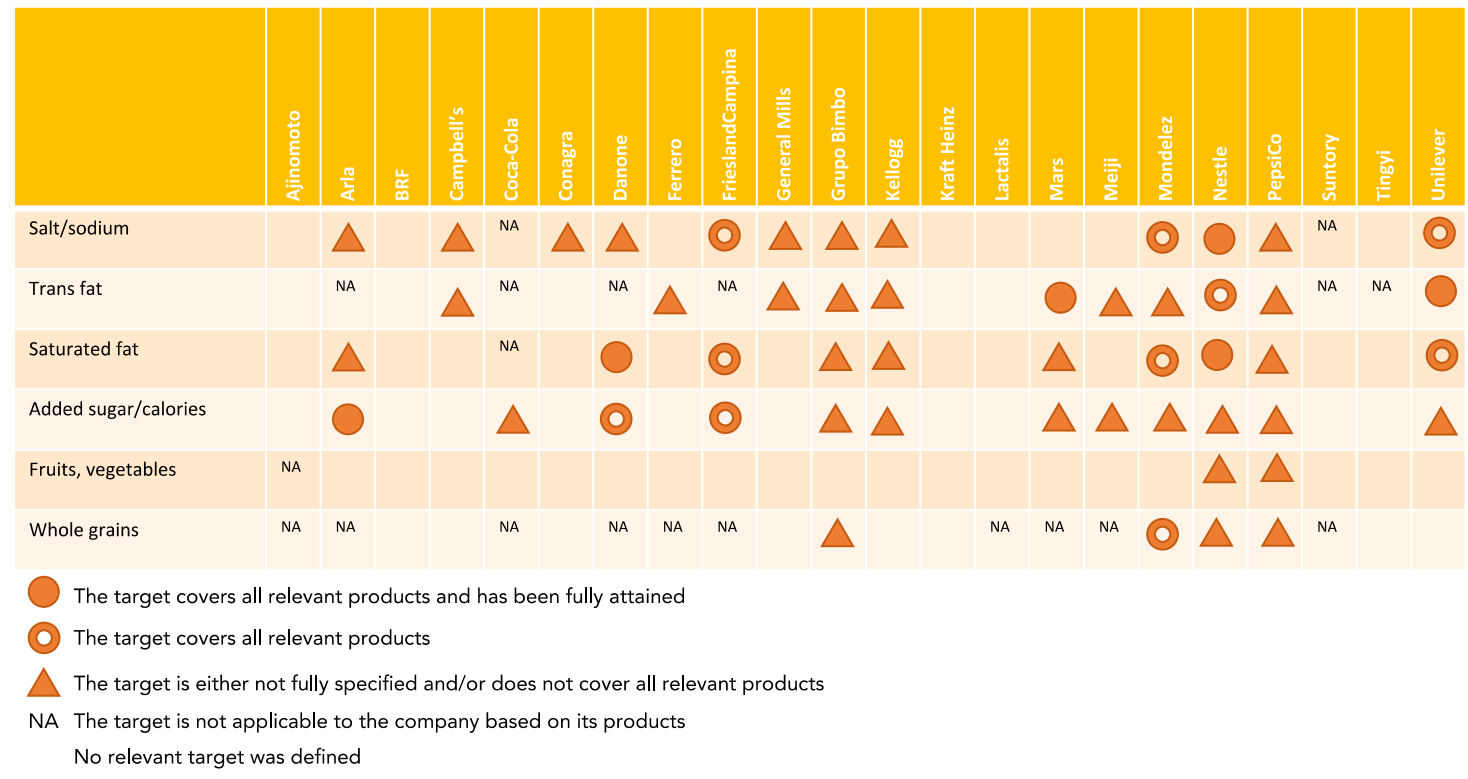

Source: Adapted from ATNI 2018

\section{The purpose of reformulation}

While the main focus on reformulation from a public health standpoint, and in this paper, is on its potential to improve nutrition and health, it has other purposes from an industry standpoint. Reformulating food can be done to decrease cost and increase profits, meet changing consumer preferences and tastes for healthier products, tap into new consumer markets to offset declining sales or add new ones, and comply with formal regulatory directives where they exist. It can also be used to change a company's overall image from an increasingly irrelevant or irresponsible player to an innovative, responsive one. One interview with industry discussed how the first reformulation a product undergoes is usually to decrease the cost and make the product more profitable either by changing an ingredient, such as 
removing natural vanilla, which is expensive, or by changing the production process, such as decreasing the cooking time and thus saving energy costs.

In one interview with an academic, they noted that they perceived increasing profit to be a significant motive for the food industry. While the individual consumer-facing businesses that make up food corporations may present motives such as making foods healthier, they must also weigh that goal with shareholder profits. They stated,

"At the business level, a brand might be reformulating for a higher purpose, and to cooperate, but that is a psychological description. A more technical description would be at a corporate level, a brand is legally obliged to maximise shareholder value and there is no getting away from that. So, recognising that there are different marketplaces where there are consumers who desire reformulated food and consumers who do not and developing countries that have lax regulation and so-called developed countries that have tighter regulation, a company is driven to reformulate for profit maximisation reasons. That is it. It is profit - if it was for any other reason, it would be very suspect." (Academic Respondent)

In another interview with a researcher, they provided a similar perspective on the food industry's motivation to reformulate, stating,

"It started as a business case, trying to improve the profile of the product to get a one-up on their competitors, to make their product stand out in some way from other products. Over time, around 2000 or 2003 when childhood obesity became a hot political topic in the United States, you could see it shift into, 'We are doing it for health reasons and because we need to be a responsible company to take action on childhood obesity.' Childhood obesity was one of the first triggers, I think it is much easier for everybody to act on children first. The real intention behind it is to circumvent other potential policy measures, which would be more restrictive to their business model. Things like taxes, VAT adjustments, restrictions on marketing, all of these would be very challenging for these companies to overcome whereas it is relatively easy to swap out one ingredient for another in an existing product and they can continue to market it in the same way to the same people. As far as policy options go, it is the lesser of evils for them, and it shows that they are being proactive, it shows that they are being part of the solution, it means that they can join these public private partnerships, which lend a lot of credibility to them as political actors and there are a lot of benefits it brings to them, and that is probably the real reason why they are doing it. I think they are definitely trying to avoid some reputational damage by taking corrective steps." (Academic Respondent)

Interviews with food industry often cited public health as the primary reason as well as citing cost, consumer demand, and environmental sustainability. One interview was characteristic of this, stating, 
"The first [reason] is public health, we very much use reformulation to address over- and undernutrition... and certainly reducing the levels of sugar, sodium, trans fats, etc. is very important. And you need a lot of science and a lot of technology to do this. People sometimes do not understand why it is not all happening fast, and sometimes it is because the science part is tricky, the technical parts are tricky, but also - which leads me to the second [reason] consumer demand. We have to also consider what consumers are looking for. It is a marriage of the two, and that is where we as nutritionists come in, because we would say there is a demand for more flexitarian and vegetarian diets, for example, so let us look at more plantbased foods, and of course we also look at the environment - we could use that as the third reason - the environmental impact. As we are doing that, we are also saying, as nutritionists, that is great but make sure it is nutritionally sound, that the nutrients are meeting public health recommendations and that it is a nutritious product." (Industry Respondent)

\section{Removing harmful ingredients}

Reducing the amount of salt, added sugar, saturated and trans fats, and other ingredients as well as the energy density in processed foods has been done to decrease consumers' dietary intakes. "Since the 1970s, food companies have been selectively and randomly reengineering individual products with reduced levels of one or more of these 'bad' nutrients or components, including reduced-fat, reduced-calorie and reduced-sugar products. These 'reduced' products are typically niche products that would sit alongside a company's original range of products, and that were presented as a choice for consumers" (Nestle 2013).

However, it is important to avoid mal-substitution, or replacing one ingredient with another that is even worse for health, making the product unhealthier, as will be discussed in greater detail later (Campbell et al. 2019; Scrinis and Monteiro 2018; Scrinis 2016). The challenge for food industry scientists is to look for other ingredients to substitute for harmful ingredients while maintaining product appearance, taste, texture, shelf-life, cost, and other attributes. An additional challenge is that every food reacts differently to the removal of ingredients, making the food science and chemistry all the more complex.

Examples of removing harmful ingredients include:

- $\quad$ Reducing salt content in chips, breads, processed meats, canned soups, and sauces

- $\quad$ Reducing sugar in cookies, cakes, candy, and other confectionery

- $\quad$ Reducing fat content in milk, yogurt, cheese, and other dairy products

- $\quad$ Reducing trans fats in crackers, cookies, cakes, and other food products

\section{Salt}

The ongoing reduction of salt has been one of the largest global food reformulations, with $47 \%$ of countries having either voluntary or mandatory legislation aimed at reducing salt, as shown in Figure 1 and Table 4 (WHO 2017). Salt reductions have largely been achieved through slow, incremental changes that allow consumers to change their tastes and become 
accustomed to lower levels of salt without changing products (National Heart Foundation of Australia 2012).

Figure 1: Countries with salt reduction strategies

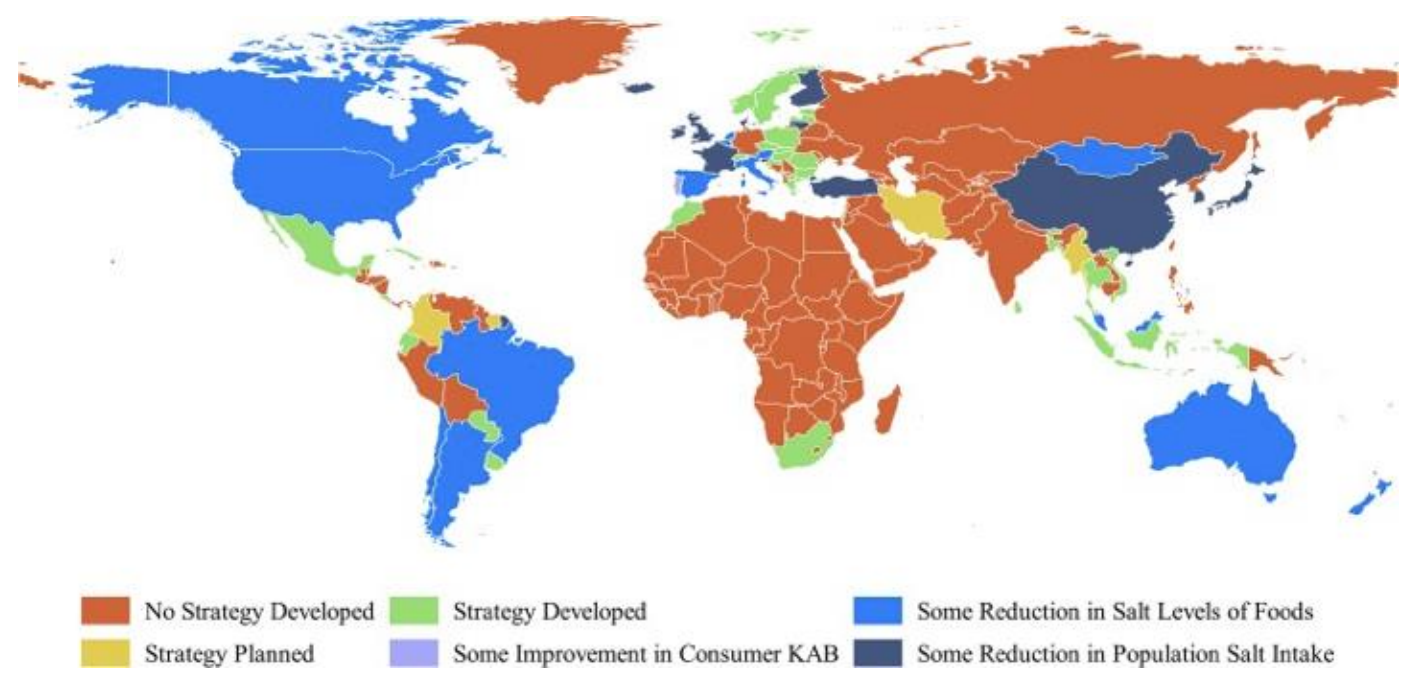

Source: Trieu et al. 2015. Permission for reproduction not required (CC BY).

Table 4: Countries with legislation to reduce salt

\begin{tabular}{|l|l|}
\hline Type of legislation & Country \\
\hline Mandatory salt targets & $\begin{array}{l}\text { Argentina (most foods), Belgium (bread), Bulgaria (bread, milk products, } \\
\text { meat products, lutenica), Greece (bread, tomato products), Hungary } \\
\text { (bread), Netherlands (bread), Paraguay (bread), Portugal (bread), South } \\
\text { Africa (most foods) }\end{array}$ \\
\hline $\begin{array}{l}\text { Taxation of high-salt foods } \\
\text { labelling }\end{array}$ & Fiji (MSG), Hungary, Portugal \\
\hline $\begin{array}{l}\text { Standards for salt as part of } \\
\text { procurement policies in } \\
\text { public institution settings }\end{array}$ & $\begin{array}{l}\text { Argentina, Brazil, Bulgaria, Cook Islands, Costa Rica, Estonia, Finland, } \\
\text { France, Greece, Hungary, Israel, Korea, Kuwait, Latvia, Lithuania, Malaysia, } \\
\text { Mexico, Romania, Slovenia, Spain, Sweden, USA, UK }\end{array}$ \\
\hline \begin{tabular}{l} 
Portugal, Thailand (on five snack food categories) \\
\hline
\end{tabular}
\end{tabular}

Source: Trieu et al. 2015

The European Union created a voluntary salt initiative, the European Union Salt Reduction Framework, as part of their 2007 Strategy for Europe on Nutrition, Overweight, and Obesity. The goal was to reduce salt in all food products by $16 \%$ over four years and also reduce salt in restaurant and catered food. A survey found that all countries had salt reduction initiatives, 25 countries had negotiations and two had discussions with the food industry, 13 had concrete agreements and five had quantifiable commitments with food companies, and 15 had surveillance in place (European Commission 2012). The United Kingdom created the Responsibility Deal with the goal of decreasing salt by 20 to $30 \%$ in food products, which resulted in a 15\% decrease in dietary salt intake (Buttriss 2013). Another study looked at the 
combination of reformulation with consumer education and resulting consumer behaviour change in the United Kingdom and found that all of the reduction in salt intake was from reformulation, not from consumer education or behaviour change (Jaenke et al. 2017; Griffith et al. 2014). This initiative was cited as one of the biggest successes in several interviews, with one person stating, "There is strong evidence from the UK that the salt reduction reformulation programme led by the government successfully reduced salt in products and that had knock-on positive effects on public health." (Academic Respondent)

Brazil also set voluntary targets for salt, which led to decreasing salt by 8 to $34 \%$ in half of food products over seven years. While most reformulation around salt has been voluntary, Argentina, Belgium, Bulgaria, Greece, Hungary, Netherlands, Portugal, and South Africa have set mandatory limits (Goryakin et al. 2019). However, in Argentina most food products were already meeting these and in South Africa there have been problems with monitoring and enforcement (Vandevijvere and Vanderlee 2019). Voluntary and mandatory reformulation have also been done in parallel, such as in Belgium where a $2 \%$ limit on salt in bread was mandated but the food industry also carried out voluntary reformulation in all foods to reduce levels of salt even further (Goryakin et al. 2019).

Several countries have reduced dietary salt intake, some dramatically, as shown in Table 5 (Trieu et al. 2015). One report detailed how Finland decreased dietary salt intake by three g/day over 25 years, the United Kingdom decreased salt by $1.5 \mathrm{~g} /$ day over twelve years, and France by $0.4 \mathrm{~g} /$ day over five years, all resulting from voluntary reformulation (National Heart Foundation of Australia 2012). However, not all reformulation efforts have been as effective at decreasing dietary intake. A report by Food Drink Ireland (2017) reported that salt decreased by $28 \%$ in 235 voluntarily reported products; however, the same report said that dietary salt intake had not gone down (Food Drink Ireland 2017). This shows that not all reformulation efforts are as successful.

Table 5: Reductions in dietary salt intake of populations by country

\begin{tabular}{|l|l|l|l|}
\hline Country & Measurement tool & Reduction in population salt intake & Timescale \\
\hline China & Dietary survey & $28.8 \%(16.8 \mathrm{~g}$ to $12 \mathrm{~g})$ & $1991-2009$ \\
\hline Denmark & Spot urine & $\begin{array}{l}7 \%(10.68 \mathrm{~g}(\mathrm{~m}), 7.51 \mathrm{~g}(\mathrm{w}) \text { to } 9.88 \mathrm{~g}(\mathrm{~m}), 7.02 \mathrm{~g}(\mathrm{w}) \\
\text { (median salt intake) }\end{array}$ & $2006-2010$ \\
\hline Finland & Mixed (dietary survey and 24 hour urine) & $36 \%(13 \mathrm{~g}(\mathrm{~m}), 11 \mathrm{~g}(\mathrm{w})$ to $8.3 \mathrm{~g}(\mathrm{~m}), 7 \mathrm{~g}(\mathrm{w})$ & $1979-2007$ \\
\hline France & Dietary survey & $4.9 \%(8.1 \mathrm{~g}$ to $7.7 \mathrm{~g})$ & $1999-2007$ \\
\hline Iceland & Dietary survey & $6.0 \%(8.4 \mathrm{~g}$ to $7.9 \mathrm{~g})$ & $2002-2010$ \\
\hline Ireland & Dietary survey & $13.6 \%(8.1 \mathrm{~g}$ to $7 \mathrm{~g})$ & $2001-2011$ \\
\hline Japan & Dietary survey & $23.0 \%(13.5 \mathrm{~g}$ to $10.4 \mathrm{~g})$ & $1997-2012$ \\
\hline Korea & Dietary survey & $13.6 \%(13.37 \mathrm{~g}$ to $11.55 \mathrm{~g})$ & $2005-2012$ \\
\hline Lithuania & Dietary survey & $18.6 \%(10.75 \mathrm{~g}$ to $8.75 \mathrm{~g})$ & $1997-2007$ \\
\hline Slovenia & 24 hour urine & $8.9 \%(12.4 \mathrm{~g}$ to $11.3 \mathrm{~g})$ & $2007-2012$ \\
\hline Turkey & 24 hour urine & $16.7 \%(18.01 \mathrm{~g}$ to $15 \mathrm{~g})$ & $2008-2012$ \\
\hline United Kingdom & 24 hour urine & $14.7 \%(9.5 \mathrm{~g}$ to $8.1 \mathrm{~g})$ & $2001-2011$ \\
\hline
\end{tabular}

Source: Adapted from Trieu et al. 2015

Additionally, more can be done. One review looked at 50 studies to determine how dramatically salt could be reduced in different products while still maintaining consumer acceptance. The review found that salt could be reduced by $37 \%$ in breads and $67 \%$ in processed meat without any reduction in consumer acceptance. Cheese was more difficult, with consumer acceptance falling by more than $20 \%$; however, 25 to $30 \%$ of salt could be 
replaced with potassium chloride in cheese while maintaining consumer acceptance (Jaenke et al. 2017).

\section{Sugar}

Reformulation efforts to decrease added sugar intake have not been as widespread or successful as those aimed at salt. While there is still promise, many have argued that the same successes seen with salt are not possible with sugar. A review determined that reformulation has the potential to decrease sugar intake by $11.2 \%$ or $91.0 \mathrm{~g} /$ day (Hashem, $\mathrm{He}$, and MacGregor 2019). However, this was low-quality evidence. Another study looked at the potential health impacts of reducing sugar intake by Australian children by modelling reformulation that would reduce added sugars by 10,15 , and $25 \%$ by simply removing sugar, replacing it with non-nutritive sweeteners, or with non-nutritive sweeteners and polyols, fibres, or maltodextrin. The study found that the scenario with $25 \%$ reduced sugar would decrease sugar intake by $11.7 \mathrm{~g} /$ day (Yeung et al. 2017).

The United Kingdom set a voluntary goal of reducing intake of added sugars to the recommended $5 \%$ of total energy intake and for the food and beverage industry to reduce the amount of sugar they use by $20 \%$ by 2020 . However, these efforts have been unsuccessful (Goryakin et al. 2019). An expert workshop was conducted to evaluate this goal and identify the challenges in reaching it. The panel concluded that the food industry could not meet this goal but could incrementally decrease added sugars by both decreasing the sweetness of foods and drinks and by replacing sugar with non-nutritive sweeteners such as acesulfame-K, aspartame, neotame, saccharin, sucralose, and steviol glycosides. The panel argued that the use of these sweeteners needs to be expanded and their use allowed in all products, instead of the current United Kingdom regulations that only allow them to be used when added sugar is reduced by $30 \%$ or in sugar-free products (Gibson et al. 2017). However, the Union of European Beverages Associations voluntarily aimed to decrease added sugar in beverages by $10 \%$ by 2020 , and an independent audit concluded that they had reached a $11.9 \%$ reduction by 2017 . In Singapore, seven beverage makers, which represent $70 \%$ of the sugar-sweetened beverage market, volunteered to reduce sugar in their drinks to a maximum level of $12 \%$ or below by 2020 (Goryakin et al. 2019). While reformulation should still be part of the strategy for reducing sugar, an interview with an academic respondent argued that labelling and taxes would be more effective.

\section{Saturated fat}

In the 1960s and 70s there were two competing hypotheses: one that saturated fat was the biggest threat to our health, increasing the risk of obesity, diabetes, and cardiovascular disease, and the other that the largest threat was refined carbohydrates and added sugar (Temple 2018; Leslie 2016). The sugar industry funded research on the negative health impacts of saturated fat, that hypothesis won out (Temple 2018), and, in 1980, the United States issued its first dietary guidelines. People were advised to limit saturated fat and cholesterol in their diets. "The guidelines shaped the diets of hundreds of millions of people. Doctors base their advice on them, food companies develop products to comply with them" (Leslie 2016). The guidelines also impacted dietary advice and policies in other countries, 
including the United Kingdom. This led to a deluge of reduced-fat, low-fat, and no-fat food products. One example is the increase in consumption of skimmed milk. In the United Kingdom, people have shifted towards drinking more skimmed milk with lower levels of fat and saturated fat. Between 2003 and 2013, whole milk consumption went down from 30.4 to 14.8 litres/capita/year while consumption of semi-skimmed went up from 48.2 to 51.8 litres/capita/year and consumption of skimmed went up from 8.0 to 8.1 litres/capita/year, despite overall milk consumption going down (Munday and Bagley 2017).

In other foods, some of the removed saturated fats were replaced with trans fats.

Additionally, in order to make these products palatable, food companies added more sugar. Unfortunately, these changes did not ease the growing rates of obesity, diabetes, and other NCDs, which continued to rise in the United States and United Kingdom. Since then, more evidence of the negative health impacts of both trans fats and added sugars has emerged (Temple 2018; Leslie 2016). A diet high in added sugar has been found to cause a three-fold increase in cardiovascular disease mortality (DiNicolantonio et al. 2015).

As efforts to remove trans fats have increased (discussed in the next section), there are additional efforts to do this without switching back to saturated fats. However, this presents challenges. In an interview with an academic, they discussed this difficulty,

"There are a lot of functional properties that fats provide in products and it is hard to get fat substitutes that meet the functional needs of these ultra-processed products and that are also okay for public health and also okay from an environmental and sustainability point of view. They are going to have a real challenge trying to figure out what to put in these products." (Academic Respondent)

\section{Trans fats}

Another key global food reformulation has been the ongoing removal of trans fats, through both voluntary and mandatory legislation. The removal of trans fats has no technical barriers, is easy to design, and the evidence of its negative health impacts on cardiovascular disease is strong (Mozaffarian et al. 2006), as is that on the positive health impacts of reformulation (Mozaffarian et al. 2010). Therefore, the case for removing trans fats is unequivocal. In an interview with an academic, they agreed, explaining, "Trans fats are in another category, the evidence on the impact of reformulation on health outcomes, cardiovascular outcomes, is the strongest by far, and that is because there is a big signal-to-noise ratio, and it is detectable, and the evidence is strong." (Academic Respondent)

A review that looked at 18 studies as well as a prior review of 14 studies compared the effectiveness of voluntary and mandatory policies to remove trans fats. It looked at both national and local trans fats bans, mandatory trans fats labelling, and voluntary trans fats limits, as shown in Figure 2. The review found that while all policies removed trans fats, bans were the most effective, as shown in Table 6. While voluntary reformulation decreased trans fats by 20 to $38 \%$ and mandatory labelling decreased them by 30 to $74 \%$, bans led to the near elimination of trans fats from the food supply. Additionally, bans were the most 
equitable, as the other measures led to increased health disparities. For example, both voluntary reformulation and mandatory labelling left more trans fats in cheaper products, while mandatory labelling relies on consumers having some nutrition knowledge. The review concluded that bans were the most effective, economical, and equitable (Downs et al. 2017). Another study looked at one public-private partnership (PPP) in the United Kingdom aimed at reducing trans fats and concluded that it was ineffective. The PPP, the Public Health Responsibility Deal, failed to attract enough participation to be effective. The pledge to reduce trans fats was only signed by eleven groups, only one of which was a food manufacturer. The others were catering companies, pub chains, universities, and an entertainment company. This study also concluded that mandatory regulatory approaches, either limits or bans or labelling, are more effective than voluntary ones (Knai et al. 2017).

There is mandatory reformulation either limiting or banning trans fats in Austria, Canada, Chile, Denmark, Hungary, and Latvia (Goryakin et al. 2019). In the two years since the Downs et al. study was published, more legislation on trans fats has been passed. The WHO released a plan to remove trans fats from the global food supply by 2023 (WHO 2018b). Bans passed in the United States and Canada in 2018 and Thailand in 2019. Singapore will ban trans fats in 2021. Many more countries and the European Union also passed trans fats regulations that will come into effect in the next two years. However, as of 2019, 110 countries did not have any legislation on trans fats, putting over five million people at risk for exposure (WHO 2019). This is unfortunate and shows that even when evidence is strong, action does not necessarily follow.

Figure 2: Trans fats policies around the world from 2005 to 2012

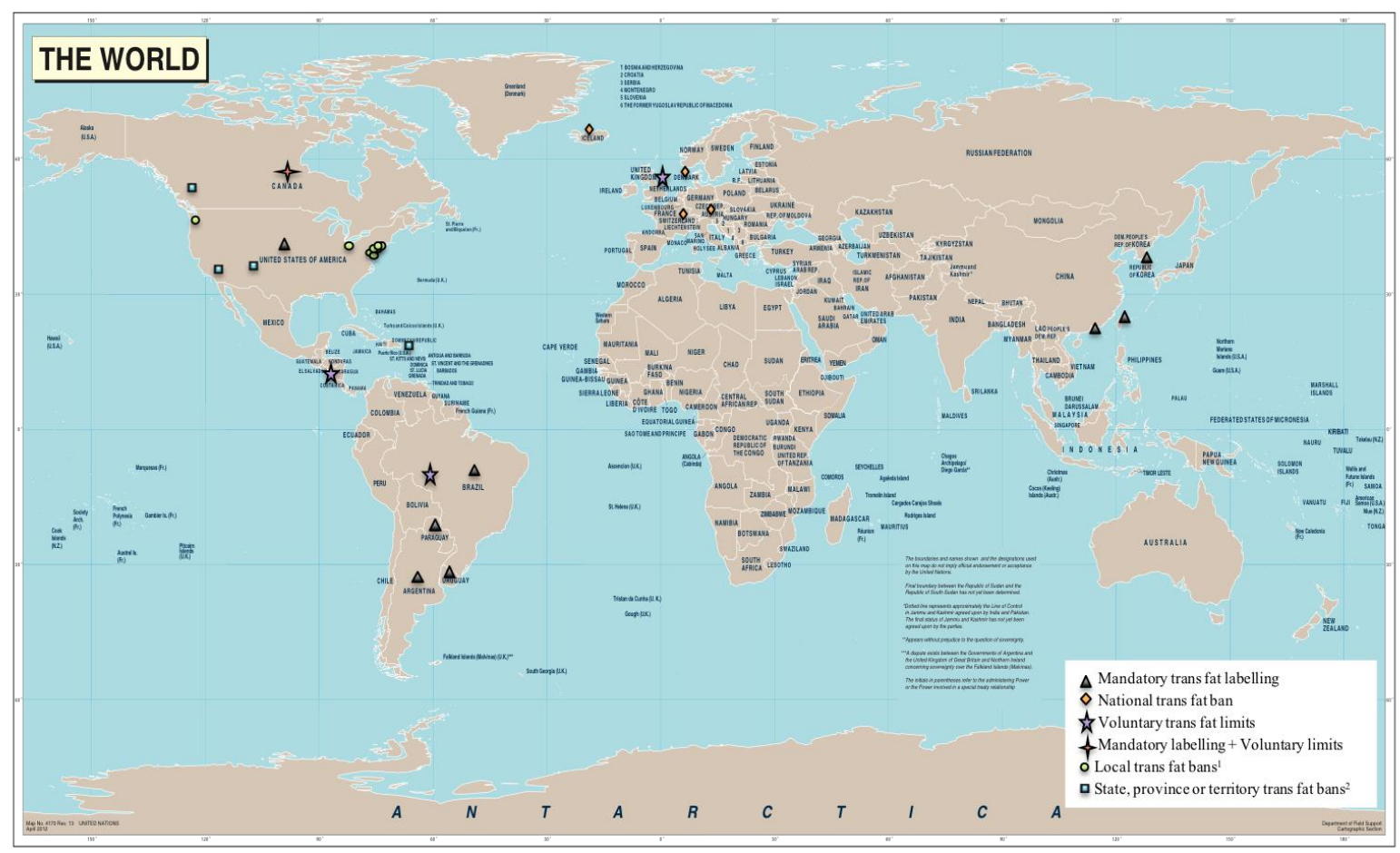

Source: Downs, Thow, and Leeder 2013. Permission for reproduction not required (CC BY). 
Table 6: Percent of foods free of trans fats after policy interventions from 2005 to 2012

\begin{tabular}{|l|l|l|}
\hline Policy Intervention & Food Category & Percentage classified as TFA-free* \\
\hline National TFA ban & All & Close to 100 \\
\hline Local TFA ban & Fried restaurant food & $95-99.5$ \\
& Other restaurant food & $92-97$ \\
& All fast food purchases & 59 \\
\hline Mandatory TFA labelling with voluntary limits & Margarines and spreads & $0-62$ \\
& Bakery products & $25-100$ \\
& Restaurant food & $50-100$ \\
& All & 76 \\
\hline Mandatory TFA labelling & Margarines and spreads & $67-79$ \\
& Fried restaurant food & 80 \\
& Supermarket food & 95 \\
& Bakery products & $42-77$ \\
& Savoury snacks & $40-100$ \\
\hline Voluntary TFA self-regulation & Restaurant frying oil & 45 \\
\hline
\end{tabular}

* In the United States, foods were classified as TFA-free if they had less than $0.5 \mathrm{~g}$ per serving. In other countries, $0.2 \mathrm{~g}$ per serving was used.

Source: Adapted from Downs et al. 2017

In an interview with an academic, they agreed with the conclusion that bans are the best course of action, stating,

"Trans fats are in a territory all on its own, it is quite different from the others, there are a handful of major industry players that create the trans fats, there is very powerful evidence showing its [health] impacts, there are very plausible alternatives that do not have an effect on consumer palatability, and it is totally appropriate and plausible for governments to regulate it out of existence, as a lot of them have. The major problem we have with the trans fats is in low- and middle-income countries where you have the big players who do not give a rat's ass about it and just want to sell products and say, 'Oh, but they demand it and; therefore, we are going to produce it.'" (Academic Respondent)

When removing trans fats, it is critical to replace partially hydrogenated oils with healthy oils higher in mono or polyunsaturated fatty acids instead of palm oil, for example, which is high in saturated fat (Downs et al. 2017). Replacing partially hydrogenated oils with palm oil has potentially harmful health impacts as well as negative environmental implications such as deforestation and biodiversity loss. One interview with a researcher discussed the problems with palm oil, stating,

"They probably will start to get some pressure to reformulate their products to remove palm oil. And, of course, the reason palm oil is in there in the first place is because they reformulated out the trans, fats which were in there to replace the saturated fats. So, you can see this vicious cycle, reformulation for the latest craze." (Academic Respondent) 


\section{Other ingredients}

Reformulation may also focus on removing other ingredients, including artificial colours, artificial flavours, and preservatives, and replacing these with natural ingredients or those that people would recognise or even have at home in their kitchens. Consumer demand for clean labels without any artificial ingredients, or for labels where they know where the ingredients come from, has driven these reformulation efforts.

"Consumers want to know what is in products, they want to know what they are eating, they want to know where things are sourced from. And there has also been a rise in either food allergies or intolerances. Our commitment to the consumer and their demands is very high, and it is important to make sure that we can satisfy that because it is a highly competitive market and we want to be a responsible producer of goods and to satisfy what consumers want." (Industry Respondent)

However, this may make it more difficult for the food industry to find substitutes for ingredients such as salt and added sugar, as discussed later. Reformulation has also served to remove ingredients that some people are unable to consume, such as lactose and gluten. Improvements in these products has led many without lactose intolerance or celiac disease to also purchase these, with around $90 \%$ of gluten-free products now purchased by people without celiac disease (Munday and Bagley 2017).

\section{Improving nutritional content}

Another one of the major reasons to reformulate food is to change the ingredients to increase healthy components, such as fibre, protein, or micronutrients, and produce a more healthful food product. Examples of improving products include:

- $\quad$ Adding whole grains or other fibre to snacks, breakfast cereals, breads, and other products

- $\quad$ Altering livestock diets to improve the fatty acid profiles of milk, butter, and other dairy products

- $\quad$ Adding healthy oils to butter spreads

- $\quad$ Adding herb extracts to cooking oils, which delays degradation and improves health properties

- $\quad$ Adding vegetables to chips, breads, and other products to increase their fibre, vitamins, and phytochemicals

- $\quad$ Adding phytochemicals, such as betalains (which have strong antioxidant properties) to foods.

\section{Fortification}

Food fortification adds essential vitamins and minerals to commonly consumed foods such as maize flour, edible oil, rice, salt, and wheat flour. Fortification may be done in order to replace micronutrients that are lost during processing, such as with cereals, or to address 
micronutrient deficiencies in the population (Das et al. 2013). It "has the dual advantage of being able to deliver nutrients to large segments of the population without requiring radical changes in food consumption patterns" (WHO 2015). For example, salt iodisation programmes have reduced the risk of goitre, cretinism, low cognitive function, and iodine deficiency in countries worldwide (WHO 2014). Micronutrient fortification of a variety of foods has been very successful in improving haemoglobin and iron status of women and children (Bogard et al. 2015; Das et al. 2013; Klassen-Wigger et al. 2018; Kumar et al. 2020)

Food fortification is considered one of the most cost-effective, proven interventions that is readily available to address vitamin and mineral deficiencies (Copenhagen Consensus 2012; Neufeld et al. 2018). Fortification spreads the burden of intervention and cost between the public and private sectors and the consumer. While it is the private sector that fortifies the food, governments can create a more enabling environment for industry by passing and enforcing legislation making it a mandatory requirement and by setting standards to ensure adequate and safe levels of nutrients are added (GFDE 2020). Moreover, when fortification is mandatory, no behaviour change on the part of the consumer is required: they benefit by continuing to eat the foods they normally buy. Voluntary fortification is undertaken at the discretion of the private sector, although preferably based on standards set by the government. Mandatory fortification is more likely to have a public health benefit because there is no need for the consumer to actively identify and choose to purchase the fortified food.

However, it is important to consider the food vehicle for fortification and its intended effect to improve public health. To this end, the 'jelly bean rule' emerged from the United States Food and Drug Administration in the 1990s, prohibiting companies from making health claims about unhealthy, highly processed foods such as candy even if they are fortified. Jelly beans may be low in fat, but companies are prohibited from marketing them as such. Additionally, even if jelly beans were fortified with vitamins, companies could not make any health claims based on that; this restriction has discouraged fortification of such foods.

The issue of which foods are appropriate to fortify has resurfaced and has been a source of controversy. In one example, in Nepal, highly processed instant noodles are widely consumed. Over four million packages of these noodles are consumed in the country every day, with Nepal being the third largest per capita consumer worldwide (Heaton 2019). This led President Bidya Devi Bhandari to start the Baliyo Nepal project, supported by the Chaudhary and Gates Foundations, to fortify these noodles to address micronutrient deficiencies. However, the move to fortify this unhealthy, highly processed food has been criticised by many. One of the country's leading nutritionists, Dr Aruna Uprety, resigned over the controversy, stating, "I am ashamed to have been part of the vested interest of a company that promotes junk food," and continuing, "This has seriously harmed my yearslong initiatives against the promotion of junk food and raises questions about my credibility" (Poudel 2019). Adding to the controversy is the fact that the Chaudhary Foundation is the philanthropic arm of the Chaudhary Group, the company that makes Wai-Wai instant noodles, leading some to ask "if the Baliyo Nepal project was created for the fortification of junk food by Nepal's largest junk food producer" (Poudel 2019). 
This question of which foods to reformulate or fortify is an emerging challenge that was discussed in most of the interviews. The majority of the interviews agreed that fortifying unhealthy foods was not a long-term solution to address public health. Thus, there is a critical need to be thoughtful and discerning about which foods are reformulated and fortified and why.

\section{Fibre}

Fibre is one of the most common beneficial ingredients added in reformulation. It is an important component of healthy diets and is linked to positive health impacts on cardiovascular disease, diabetes, and some types of cancers (Whelton et al. 2005; Lairon et al. 2005; Montonen et al. 2003; Steffen et al. 2003; Keenan et al. 2002; Brown et al. 1999; Liu et al. 1999). While the health impacts are clear, it can be difficult to add fibre without drastically changing a food product. In one interview with industry, they discussed work to increase fibre and the corresponding challenges,

\footnotetext{
"Over the years, we have made big pushes on fibre inclusion. That is so tricky though because you are fundamentally changing [the product]. For sodium, if you look at the percentage in the recipe, it is absolutely miniscule so, while it is technically difficult to reduce sodium as an ingredient, it is way easier than adding fibre, which is a big proportion of the recipe, because you are fundamentally changing the product, and in some matrices, it might be easier, but when you have a simple grain, which is a lot of our cereals, it is really, really hard to add fibre to that." (Industry Respondent)
}

Despite the challenges, there have been successful efforts to add fibre and whole grains to foods. In Denmark, the Whole Grain Partnership was a voluntary reformulation initiative to increase whole grain intake by setting standards for the amount of whole grains products had to contain, as well as limits for salt and sugar, to get a certification logo on their packaging. This led whole grain intake to increase from 36 g/day in 2007 to 63 g/day in 2014 (Goryakin et al. 2019).

\section{Healthy oils}

Mono- and polyunsaturated fats also have positive health impacts on cardiovascular disease. Omega-3 fats are especially valued for their health benefits. Many products, including breads and cereals, have been reformulated to include omega-3 fats. It is unclear if these foods have had a positive impact on health.

\section{Probiotics}

An increased interest in the human microbiome has led to probiotics, or live microorganisms that have health benefits, to be added to more food products. The global retail value of probiotics was over 49.4 billion USD in 2018 (including supplements) and is expected to increase to 69.3 billion by 2023 (Markets and Markets 2019). The specific probiotics added are often chosen for their health benefits, such as improving gastrointestinal function, relieving bloating or constipation, increasing immune function, improving allergies and 
asthma, and even improving skin conditions, although the evidence behind many of the claims in limited. While probiotics are naturally occurring in unpasteurised fermented foods, they are also added to yogurt and other fermented milk products. Probiotics have also been added to bottled smoothies and juices, snack bars, chips, brownies, and cookies.

\section{REFORMULATION: HOW AND WHY IT IS DONE}

\section{Voluntary reformulation}

To date, most reformulation has been voluntary. Most of the interviews with the food industry argued that reformulation should be voluntary, with some arguing that the government does not understand the process and challenges and thus is ill-equipped to set mandates. One interview with industry suggested that reformulation should be voluntary, with a cap and trade approach; this would allow industry to decide which products to reformulate, with a focus on products with the largest sales, to make the largest impacts. This same interviewee argued that an important benefit of voluntary reformulation is that it can occur much faster.

While voluntary reformulation has allowed change to happen without political action (Vandevijvere and Vanderlee 2019), which may make reformulation easier and faster, it has limitations. Voluntary reformulation allows the food industry to set their own agenda as well as monitor and evaluate themselves. The food industry can set their own targets, which may or may not be in line with public health targets, decide how many products to reformulate, at what levels, and over what time period as well as deciding whether to leave un-reformulated products on the shelf. Some have argued that the food industry has too large a conflict of interest to be a genuine partner in reformulation (Kaldor 2017). Additionally, there is no accountability for meeting these targets or not. This results in food companies continuing to sell unhealthy products, both those that have been reformulated and those that have not (Campbell et al. 2019). Other companies have pledged to reduce harmful ingredients by certain amounts, but this is not enough, especially for products that have very high initial levels of these. For example, if a breakfast cereal has 30\% added sugar, a 20\% reduction of added sugar still results in a product with 24\% added sugar (Scrinis 2016).

Voluntary reformulation also leads to uneven coverage, with some products being reformulated and others not, so consumers still have the option of buying products with high levels of salt, sugar, and unhealthy fats. One interview with industry discussed how consumers can just switch from a reformulated product to one that has not been changed, stating,

"Contra to pharma, where the product that is brought to the marketplace needs to be prescribed by a physician, approved by the payer, and then validated by your insurance company, where as the patient you completely lose control over what medicine you take for whatever ailment, in this industry, nobody is forcing anybody to do anything, so this is incredible because this enormous base of consumers votes with their feet and their money on the quality and texture and hedonic properties of our products in the marketplace all the time.

So, one of the things that you cannot do in these efforts that are very well-supported by science and very well-meaning is alienate your consumers, because the risk is two-fold. There is not only a commercial risk, but if you try to do something that you believe is good for the 
health of your consumers and you do it in the wrong way or too quickly and they don't follow you, you have lost not only a commercial opportunity, but also an opportunity to do good on the health of your consumers. And I do not think that even people who talk about nutrition a lot understand how this intricate dynamic between somebody who puts food out there in the marketplace and the consumers that end up consuming it is fundamental to how quickly you can move the needle." (Industry Respondent)

Additionally, if products that are not consumed in large quantities are reformulated, even significantly, this may not make any impact on dietary intake. One interview with an academic described this, saying,

"There is a tendency for the media to see foods outside of the context of their contribution to diets. This then influences policymakers. It is thus essential that target foods be identified based on their contribution to the intake of the target nutrient. You can reformulate Christmas pudding [a holiday dessert popular in the United Kingdom], but its public health impact will be near zero. On the other hand, a small change in the sodium content of bread will have a significant impact on sodium intakes. Bread is a significant contributor to sodium intake and bread has a high population diet penetration." (Academic Respondent)

After a company reformulates a product for one market, such as Europe, they can continue to sell the original product in other markets with less demand or regulations around reformulation. One interview with an academic pointed this out as a limitation of voluntary (or even mandatory) reformulation at the national level and argued that there needs to be transnational reformulation, stating,

"When the United States or European Union starts to button up on food reformulation, you see transnational companies move to less-regulated markets. So, it is a transnational common dilemma, kind of like climate change, like so many other problems. It cannot be dealt with at a national level." (Academic Respondent)

Independent evaluations have questioned the accuracy of industry reports of their successes. For example, the Healthy Weight Commitment Foundation in the United States claimed to have removed 6.4 trillion calories from the food supply; however, independent verification found that calories were already declining and would have reached this same level without the group's efforts (Mozaffarian 2014; Ng, Slining and Popkin 2014).

Another example is from Food Drink Ireland, which released a report detailing their successes with product reformulation from 2005 to 2017. The report compiled voluntary industry data submissions and claimed that there was a $28 \%$ reduction in salt, $8 \%$ reduction in sugar, $0.3 \%$ reduction in total fat, $10 \%$ reduction in saturated fat, and $1.6 \%$ reduction in calories. However, this was only for 235 unidentified and voluntarily reported products. They also 
reported that there was no change in dietary salt intake. When trying to explain this discrepancy, the report offered that, "one possible explanation is that the products submitted by the participating companies do not include many of the biggest contributors to salt intake in Irish diets" (FDI 2018). For those who just quickly looked at the statistics, they may have missed this discrepancy. One interview with an academic discussed how it was problematic for the food industry to choose the variables and measurement tools for monitoring and evaluation as well as control the data. The food industry can then use "a very subtle shaping of measurement tools that are acceptable" (Academic Respondent) to distort results.

One interview with a researcher discussed many of these shortcomings of voluntary action, stating,

\footnotetext{
"In terms of why voluntary reformulation does not drive the kinds of changes that would lead to public health benefits, it has to do with it not being a level playing field, not all companies do it and there are competitive reasons not to reformulate their best sellers because they do not want to lose out on market share to somebody who has not reformulated their product. We also see things happen in a voluntary initiative where companies can set their own product portfolio targets in such a way that they can meet their targets primarily through obtaining new products that are healthier than their existing products. You could argue that is a good

thing, that they are shifting and their business model is diversifying, but they are not changing the nutritional composition of their bestsellers and those are what people are consuming the most of, the small niche brands that they are buying are not the big sellers."

(Academic Respondent)
}

Another critical shortcoming of voluntary reformulation is that it allows the food industry to shift the conversation and approach away from mandatory reformulation (Koplan and Brownell 2010). There are "numerous reasons to suggest that voluntary reformulation plays a role in the industry's strategy to avoid unfavourable regulatory conditions, and this finding warrants significant consideration" (Scott et al. 2016).

\section{Negative incentives for industry to reformulate}

Not all incentives to reformulate are positive. Negative incentives include pressure from governments and public health groups such as the WHO. This pressure often leads to voluntary reformulation in an attempt by the food industry to avoid more comprehensive government action, such as legislation ranging from labelling and taxes to ingredient and nutrient limits or bans.

Other negative incentives include competition with other food companies that are also reformulating their products and posturing themselves as being better for health or the environment as well as the need to change products in response to a shortage or increase in the cost of ingredients or the need to improve food products in terms of their appearance, taste, texture, cost, shelf-life, or other attributes. One interview addressed this, stating, 
"There are factors that influence reformulation and reformulation options like supply, availability of alternative raw materials and ingredients, the functionality of ingredients that are being taken out or added and the impact on texture, mouthfeel, and taste - which are only part of those functionalities - the element of the label that is one of the key aspects, you do not

want to replace an ingredient with a few different ingredients and make the label more complex, the impact that those ingredients have on the stability and; therefore, the shelf-life, and the safety during that shelf-life of the food product." (Industry Respondent)

\section{Labelling}

Labelling is a large stimulus for the food industry to reformulate, particularly if the labelling constitutes warning labels on food products. There can be requirements to label harmful ingredients or nutrients, such as the United States' upcoming requirement to label added sugars. One study modelled the expected effect of this new labelling requirement with and without anticipated corresponding reformulation of reducing added sugar by $25 \%$ in 7.5 to $9 \%$ of products over three years. The study found that labelling alone was expected to prevent 354,400 cases of cardiovascular disease and 599,300 cases of diabetes, save 727,000 quality-adjusted life years (QALYs), 31 billion USD in healthcare costs, and 61.9 billion USD in overall societal costs. Labelling and reformulation combined were expected to prevent 708,800 cases of cardiovascular disease and 1.2 million cases of diabetes, save 1.3 million OALYs, 57.6 billion USD in healthcare costs, and 113.2 billion USD in overall societal costs between 2018 and 2037. The large difference shows that while mandatory food labelling is useful in changing consumer behaviour, reformulation is also important, and the two together are even more effective (Huang et al. 2019).

Simple, easy-to-interpret front-of-pack (FOP) labels that include stars, traffic lights, or other assessments of nutrition and health as well as warning labels are also increasingly being used. The food industry may choose to reformulate products in order to avoid getting a low rating or a warning label (Vandevijvere and Vanderlee 2019). Australia and New Zealand introduced the voluntary Health Star Rating system, as described above. One study looked at 252 packaged foods aimed at children in Australia in 2013 before the HSR system was introduced and afterwards, in 2016 . They found that $65 \%$ of the products that adopted the HSR were reformulated. Products with the HSR had less saturated fat and calories and more fibre and protein. However, as the HSR was voluntary, very few products adopted the label and overall the packaged foods were considered unhealthier in 2016 than in 2013 (Morrison et al. 2018).

Another study found that only $6.7 \%$ of products adopted the HSR but that these products had a $7.11 \mathrm{~kJ} / 100 \mathrm{~g}$ decrease in energy density. The study concluded that the HSR lead to a 0.98 calorie decrease in calorie intake per day but that it could lead to a 11.81 calorie decrease if it was mandatory (Herrera et al. 2018). A study in New Zealand also looked at packaged foods in 2016 and found that only 5.3\% of packaged foods adopted the HSR but that these products had less salt, sugar, and saturated fat and more fibre than those that did not. Of these products, $83 \%$ were reformulated to reduce salt and energy density and increase fibre (Mhurchu, Eyles, and Choi 2017). Other voluntary FOP labels have been introduced, such as the Nutri-score in Belgium, France, Germany, and Spain as well as others 
in the Netherlands and Canada, and warning labels have been introduced in Chile (see Box 3) and are being developed in Canada, Israel, and other countries in Latin America (Vandevijvere and Vanderlee 2019). 


\section{BOX 3: CHILE'S JUMPSTART ON FRONT-OF-PACK LABELS}

Like many other countries, Chile faced rapidly rising levels of overweight and obesity as well as NCDs. This was at least in part attributable to the large amount of highly processed foods consumed, making up almost a third of total dietary energy intake and over half of total added sugar intake in 2010 (Cediel et al. 2017). In 2007, Chile developed the Law of Food Labeling and Advertising (Law 20.606). This law utilised the International Network for Food, Obesity, and Non-Communicable Diseases Research, Monitoring, and Action Support (INFORMAS) framework. The law specifies limits for salt, sugar, saturated fat, and calories and requires packaged foods that exceed these limits to carry a FOP warning label for each nutrient that exceeds the limit, as shown in Figure 3. Therefore, a packaged food may have up to four FOP warning labels. Additionally, foods with warning labels are prohibited from being sold or offered at schools and day cares and cannot be marketed to children under 14 years. This was passed in 2012 and implemented in 2016, with increasingly stricter limits in 2018 and 2019.

One study that investigated the effectiveness of the marketing limits found that pre-schoolers' and adolescents' exposure to food advertising for products high in salt, sugar, saturated fat, and calories decreased by 44 and $58 \%$, respectively, and exposure to advertising with cartoon characters or other components directed at children decreased by 35 and 52\%, respectively. While the law effectively lowered children's exposure to this advertising, it did not eliminate it (Carpentier et al. 2019).

Figure 3: FOP warning labels for foods high in salt, sugar, saturated fat, and calories
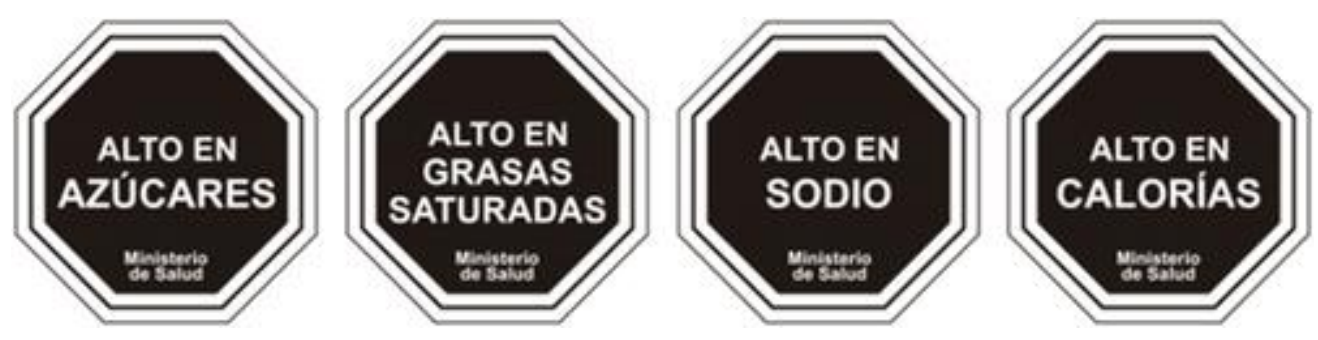

Source: Kanter et al. (2019b)

A study aimed to estimate the prevalence of foods that would carry the warning labels in 2016 and after the stricter limits were implemented in 2019. In 2016, it was estimated that $62 \%$ of foods would carry at least one warning label, with $16 \%$ of these carrying two warning labels, $16 \%$ carrying three, and $0.03 \%$ carrying all four. In 2019 , it was estimated that $83 \%$ of foods would carry at least one warning label, with $25 \%$ of these carrying two warning labels, $23 \%$ carrying three, and $0.60 \%$ carrying all four. Overall, the proportion of foods with no warning labels was estimated to be only 38\% in 2016 and even lower at 17\% in 2019. Additionally, in $2019,70 \%$ of food categories were estimated to have over $80 \%$ of their products having at least one warning label (Kanter et al. 2019a). Prior to the law, there was some reformulation to avoid the warning labels, but only a few products, fewer than $2 \%$, were reformulated to avoid at least one warning label (Kanter et al. 2019b).

One of the interviews with a researcher discussed the low levels of reformulation before the law was implemented but argued that more reformulation had occurred since then, with the interview stating, "[The warning labels] have been in graduated stages in Chile so it gives the manufacturers time to reformulate their products so they do not get the label. In order to avoid getting a warning label, the product has to have less than five grams so a lot of products get reformulated to 4.9 grams, so there are a whole lot of products just under the threshold. So the industry clearly takes notice of that." (Academic Respondent) 


\section{BOX 3 (CONTINUED)}

Despite low numbers for industry reformulation, another study found that the labels were well known by mothers and that they understood their purpose and that the more labels a product has, the less healthy it is. One mother said that the labels opened her eyes and helped her to see which food products are unhealthy. Several mothers described being surprised at how unhealthy some breakfast cereals, bars, and yogurts are. Children described the same reaction, with one five-year-old saying, "I associated that the brand Nutrabien [Goodnutrition] was very healthy, until those black labels came out. I realized that it had high levels of everything and I felt very cheated... I really had no idea, I never paid attention. Now, I do pay attention" (Correa 2019). Several of the mothers described using the labels to decide which foods to buy as well as telling their children that they needed to find food products with the fewest labels, especially when buying new products; however, others said that they did not pay attention to them. Among children, younger children were accepting of the changes in food at schools, and many had embraced healthier foods, but some older children had more problems with it (Correa 2019).

Another study looked at the impact the law had on beverage purchases and concluded that it decreased the purchase of beverages high in sugar, calories, saturated fat, and salt by 22.8 $\mathrm{mL} /$ capita/day or $23.7 \%$. This led to a decline of $11.9 \mathrm{kcal} /$ capita/day and $0.7 \mathrm{~g} /$ capita/day of sugar, but consumption of calories from other beverages increased by $5.7 \mathrm{kcal} / \mathrm{capita} /$ day. The study concluded that these impacts were larger than singular policies, such as taxes alone. In Chile, an increase in the tax on sugar-sweetened beverages only decreased purchases by $3.4 \%$ whereas Mexico's tax decreased purchases by $7.6 \%$. Additionally, while there were similar absolute declines despite differences in education levels, there were higher relative declines for households with highereducation due to lower starting purchase levels and higher health literacy. This could increase health disparities, which are already an issue in Chile, and the study advocated for more research in this area (Taillie et al. 2020).

\section{Taxes}

Another negative incentive is taxes. National and local taxes on sugar-sweetened beverages have been introduced in several countries including the United Kingdom, United States, Mexico, Chile, and others. Taxes can also stimulate reformulation, with food and beverage companies trying to avoid the taxes. In the United Kingdom, the tax was on drinks with more than five grams of sugar per $100 \mathrm{~mL}$, so companies reformulated products to keep their products from being taxed. One study found a $10 \%$ decrease in the average sugar in drinks in anticipation of the tax (Vandevijvere and Vanderlee 2019). One interview with industry argued that taxing sugar by gram would lead to the most reformulation, as this would provide a financial incentive for companies to reduce sugar in these drinks, stating,

"They could have based [the tax] on the sugar content. Then for the large companies even a half a gram removal of sugar is a huge win financially in cost avoidance. If you tax it at a penny a gram, it is massive what just a half gram reduction would deliver. It is a few million dollars and that is pure profit. And if you do the math on the profit side you usually triple that to get to the sales figure. So, one million dollars in gross profit typically has to mean 
about three to four million dollars in sales. So, it is that incentivisation to drive those kinds of changes that really, really makes a difference. And having the technology to deliver on it too." (Industry Respondent)

\section{Ingredient and nutrient limits and bans}

While most reformulation has been voluntary, as discussed above, there have been a few examples of mandatory reformulation, such as mandatory limits on salt and bans on trans fats. Mandatory reformulation has the advantage of allowing the public health sector to set meaningful targets and timelines that are based on nutrition and health research instead of industry profits. One interview with an academic discussed the importance of not allowing industry to set these targets and noted that industry should be a partner in carrying out reformulation but should not be setting the agenda or goals, stating,

"It is not the industry that we should be looking to lead reformulation. By all means, we can work with industry, but the notion that they would be partners in defining the standards for healthy food is a flawed on,e and it leads to anaemic, inadequate, attenuated, and ineffective reformulation strategies." (Academic Respondent)

Additionally, there can be independent monitoring and evaluation with meaningful consequences for noncompliance. Mandatory reformulation often requires all companies to reformulate all products, taking the burden off of the consumer. This also creates a level playing field, as some in the food industry have argued. A study that interviewed people from 17 Dutch food companies about an agreement to reduce salt, sugar, saturated fat, and energy density found that the companies wanted more government regulation to force all companies to reformulate (Van Gunst, Roodenburg, and Steenhuis 2018). Similarly, several of the interviews we conducted with industry made the same point. One stated,

"[We have] been reformulating, but if we are competing with companies that have not, and it is not a level playing field, and particularly if we put that on our labels but other companies do not, sometimes consumers have not been educated and maybe think, 'Oh, well that is not going to taste good.' To make a public health impact, we need everyone to do it. That is the important thing, and the other important thing is that when you are reducing salt and fat and sugar, it can impact taste, and that is why we all need to be doing it together." (Industry

Respondent)

In another interview, they provided the following example,

"We decided to decrease the sugar in our products, but the local producers did not change anything in theirs, and people realised that our products were less sweet, less attractive, and 
we lost a lot of sales from people switching from our brand to the local brands" (Industry

Respondent)

Additionally, products that cannot be reformulated to meet mandatory targets would be removed from shelves, improving the food supply (Scrinis 2016). Mandatory reformulation is thus more effective than voluntary reformulation (Vandevijvere and Vanderlee 2019). One report estimated that mandatory reformulation for salt in Australia would be 20 times more effective than voluntary reformulation (National Heart Foundation of Australia 2012). One interview with an academic described how mandatory reformulation would be an effective path forward for salt and added sugar reduction, stating,

"The sugar and salt are in the same basket in that we have human taste for salt and sugar, which the industry exploits, and there are some food products where sugar and salt are fundamental to the composition of the product, you cannot have chocolate without sugar, you cannot have salami without salt, so you cannot always have salt-and sugar-free products, you cannot completely get it out of the food system. But what do you do about it in a regulatory sense, and what do you do about it in a monitoring and a policy goal sense? So, the easiest thing to regulate by far is to have maximum salt and sugar levels in particular products. And yes, an individual company can be responsible and monitored and pinged for having a product which is too high in salt or sugar, but the problem is getting the average down, and whose responsibility is it to get the average down?" (Academic Respondent)

One interview with an academic discussed how the most effective path forward would include many different components, stating,

"If a government is going down this path, it cannot just be a regulatory food standard, composition criteria track, it has to be a multipronged taxation, labelling, education, regulation of the top standards, ongoing monitoring, publishing and shaming companies, and government advocacy on companies. It could and should move into the procurement space for governments, such as the US government that procures for school food or the army, which are huge levers that they could use. With a multipronged approach, you can actually change these things and you can regulate claims so that they are not putting calcium in jellybeans and making a claim that it will save your bones. It has to be a multipronged approach." (Academic Respondent)

While there are few disadvantages to mandatory reformulation from a public health standpoint, there are some disadvantages from an industry standpoint. Mandatory reformulation is difficult to design, and industry representatives often claim that it may not be technologically feasible to reformulate all their products to meet certain targets and that the reformulation process is difficult, long, and expensive, as discussed below. Industry argues that it requires significant effort, time, and money to reformulate products while maintaining 
consumer acceptance (IGD 2019; Komitopoulou and Gibbs 2012). One interview with industry also argued that mandatory reformulation would hurt small food producers, as they have less money for research and development and would face more difficulty in reformulating. One interview with industry stated,

"That is one of the reasons why only large organisations can deal with regulatory issues on an industrial basis, meaning dealing with 100 different regulations at a time for any single product, and why small start-ups are better-suited initially to concentrate on one or two targeted markets, but it is an immense issue, and it drives significant cost within these organisations because it is so disharmonised outside that you have to harmonise it inside the company, and to do that is a massive effort." (Industry Respondent)

Mandatory reformulation has also been criticised for being paternalistic and limiting consumer freedom as well as interfering with free markets. However, an ethical analysis that compared the impacts on freedom of choice of both voluntary and mandatory reformulation found that there was no difference. The same study also argued that the market for food is more complex and involves an interplay of the state, industry, and consumers and that the 'free market' is already being shaped by the food industry and governments to impact consumer demand. The study concluded, "reflecting free market ideals, governments' preference for industry schemes is likely to persist. But, given the increasing evidence linking greater state involvement with more successful food reformulation outcomes, a default preference for the 'voluntary' may start to require a stronger justification" (Kaldor 2017).

One interview with an academic pointed out that "warning labels and taxation are the two main tools government has to get reformulation happening." (Academic Respondent). Many others have argued that the most effective approach to improving highly processed foods would be a combined approach of mandatory labelling; mandatory limits on salt, added sugar, and saturated and trans fats; and taxes. The effects of each are greatest when they are mandatory, used in combination, and independently monitored and evaluated. However, mandatory actions are hardest to enforce in emerging markets, as there are more informal retailers (Vandevijvere and Vanderlee 2019). Additionally, one of the interviews with an academic added that mandatory actions are most difficult for small- and medium-sized enterprises, stating,

"The economic scale of the manufacturer is critically important. For large multinational corporations, neither budget nor technical ability is a barrier. But for small and medium enterprises, these are serious barriers. Their financial structures rarely allow vision beyond the next quarter. Moreover, the technological capacity of these companies is limited as is the market research of consumer acceptability." (Academic Respondent) 


\section{Positive incentives for industry to reformulate}

The food industry is also incentivised to reformulate by positive incentives, including market demand in response to changing consumer preferences and tastes and the increasing importance of nutrition and health for consumers as well as environmental sustainability in the face of the climate crisis. The food industry is responding to new demands to make premium or superior products as well as continual demands to make lower-cost products. One interview discussed changing consumer demands, stating, "The millennials really want to change the way that they eat compared to their parents, they are much more open to different tastes, and they want innovation even if it's not very good as long as it's okay enough for what they expect." (Industry Respondent)

The Consumer Goods Forum 2019 Health and Wellness Progress Report argues that food manufacturers have ambitions to empower consumers to lead healthier lives through reformulation. The report states that 320,000 food products have been reformulated to limit salt and sugar since 2015 and $98 \%$ of companies have reformulated at least some of their products in 70 countries (CGF 2019).

Companies want to make inroads into public health, and reformulation is seen as a contribution to positive health outcomes. A report focused on consumers in India found that $81 \%$ of consumers wanted food companies to make products healthier and only $3 \%$ of consumers believed that companies already offered enough healthy foods (IGD 2019). Food companies have incentives to make products that can be marketed and advertised to these consumers, including qualifying for positive nutrition assessments in the new labelling schemes, as discussed above.

The food industry is also responding to market demand for more environmentally sustainable products in the face of the climate crisis. However, the development of sustainability criteria to guide reformulation is still in its infancy. Spieldenner and van der Horst (2018) suggest that reformulating to address sustainability comes with a cost increase most of the time and that much of this cost is passed onto the consumer. Consumers are still hesitant about the value for money and view some of these more sustainable food products with mixed feelings. "This means a change in the marketing approach to an intelligent way of selling a product with added nutritional and sustainability value - an endeavour that needs to be carefully balanced with silent reformulation and steering clear of the breaking point of consumer acceptance" (Spieldenner and van der Horst 2018).

\section{PUBLIC HEALTH IMPACTS OF REFORMULATION}

As illustrated in Figure 4, reformulation, along with consumer-facing taxes and subsidies and consumer behaviour change, provides the opportunity to improve diets and nutrition by decreasing the salt, added sugar, saturated and trans fats, and energy density of the food supply. When in excess, these harmful ingredients and nutrients have been linked with cardiovascular disease, diabetes, and some cancers. 
Figure 4: The effect of taxes and subsidies on consumer behaviour, reformulation, diets, and NCDs

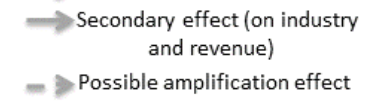

Tax \&/or subsidy-incentives for substitution with healthier foods \& beverages

Source: Thow and Downs 2016. Permission for reproduction not required (CC BY).

One interview with an academic cited these health benefits, stating,

"Reformulation can be a heavy lifter for cardiovascular disease, and this downturn that we have seen in cardiovascular disease in the 40,50 years since the '70s in your country and my country is probably in a big part due to changes in the food supply that we do not really know or measure; I am sure it has been pulling out the saturated fat, reducing the salt, maybe even that orange juice that you are drinking, getting potassium there." (Academic Respondent)

Additionally, reformulation offers a pathway to improving diets, nutrition, and health without requiring consumer behaviour change. However, it is important to remember that highly processed foods have other problematic attributes, such as being very convenient, often ready to eat, highly palatable, and strongly marketed. Reformulation can decrease harmful ingredients or nutrients, but it will not lead to the necessary larger dietary shift towards unprocessed and minimally processed foods such as vegetables, fruits, legumes, nuts, seeds, and whole grains.

Several studies have found that food reformulation could have significant public health outcomes and be more effective than policies focused on changing consumer behaviour alone (Vandevijvere and Vanderlee 2019; Spiteri and Soler 2017). One study found that a $5.1 \%$ decline in salt intake in the United Kingdom was entirely attributable to product 
reformulation; consumer switching between products worked in the opposite direction and led to a slight increase in dietary salt intake (Jaenke et al. 2017). However, it is important to note that it is not possible to discuss causation and that few reformulation programmes have been evaluated in terms of their impact on health outcomes. Evaluating the population-level impact of specific reformulation initiatives is especially difficult because of the multifactorial and distal nature of the link to chronic diseases. These challenges and limitations were discussed in many of the interviews, both with academics and the public health sector and with industry. However, this assessment will mainly examine systematic reviews on the impacts of reformulation of foods on specific disease outcomes, such as obesity and NCDs.

The health impacts of several reformulation actions have been documented, such as reductions of salt, sugar, and unhealthy fats. In Finland, reformulation led to a three g/day reduction in dietary salt intake between 1978 and 2002. This corresponded with a $10 \mathrm{mmHg}$ decrease in blood pressure and a 60 to $80 \%$ decrease in mortality from cardiovascular disease and stroke (National Heart Foundation of Australia 2012). A review of 16 studies found that reformulation reduced sugar and resulted in corresponding weight loss (Hashem, $\mathrm{He}$, and MacGregor 2019). In Mauritius, reformulation of products to use soybean oil instead of palm oil led to energy from saturated fat being reduced by $3.5 \%$ and energy from polyunsaturated fat increasing by $5.5 \%$. This led to a decrease in population total cholesterol by 0.79 to $0.82 \mathrm{mmol} / \mathrm{L}$ (National Heart Foundation of Australia 2012). In Denmark, the ban on trans fats led to a 3.2\% decrease in deaths from cardiovascular disease (Vandevijvere and Vanderlee 2019).

Several studies have also modelled the potential health impacts of reformulation. One review looked at 33 studies and concluded that they all showed potential positive health impacts of reformulation. The strongest evidence was for salt, while evidence was less conclusive for sugar and fat (Federici et al. 2019). One study found that reformulation in 42 countries could lead to 1.1 million fewer cases per year of cardiovascular disease, diabetes, and cancer, leading to a gain of four million DALYs and 3.1 million life years annually, and increasing the life expectancy by 2.9 months. These impacts could save 13.2 billion USD PPP by decreasing health care spending by $0.21 \%$, increasing the GDP of those 42 countries by $0.51 \%$ per year (Goryakin et al. 2019). Another study found that reformulation could lead to the populations of France and the United States getting much closer to meeting dietary guidelines as well as losing weight and would decrease current socioeconomic disparities in diets (Gressier et al. 2017). A third study found that reformulation in France had the potential to prevent between 2,408 and 3,597 deaths per year, which was a 3.7 to $5.5 \%$ reduction in mortality. More of these deaths were for people with low incomes, showing that reformulation would reduce health disparities. The reduction of saturated fat had the biggest health impact, with 1,897 deaths avoided, followed by sugar and salt, with 746 and 608 deaths avoided respectively (Leroy et al. 2016).

A report stated that if Australia reduced salt in processed foods by 15 to $25 \%$ over ten years, it could prevent 5,800 to 9,700 heart attacks and 4,900 to 8,200 strokes. Additionally, if the United States decreased salt intake by three $\mathrm{g} /$ day it would have the same public health benefit as cutting smoking by 50\% (National Heart Foundation of Australia 2012). 
A study, discussed above, detailed the potential health and economic impacts of reducing sugar through reformulation in response to mandatory added sugar labelling in the United States. The study found that labelling and reformulation could decrease added sugar in the United States by $8.25 \%$ to prevent 708,800 cases of cardiovascular disease and 1.2 million cases of diabetes, save 1.3 million QALYs, 57.6 billion USD in healthcare costs, and 113.2 billion USD in overall societal costs between 2018 and 2037 (Huang et al. 2019).

However, there is push-back (Federici et al. 2019). Several have argued (Campbell et al. 2019, Scrinis and Monteiro 2018; Scrinis 2016) that reformulation aimed at reducing the quantities of harmful ingredients - salt, added sugar, saturated and trans fats, and total energy density - has limitations, especially for highly processed foods where these may make up the bulk of the ingredients. They argue that one serious limitation is that by focusing on just one or a few ingredients to remove, many other highly processed, industrial ingredients are left behind that may also have harmful impacts on health. One researcher from the public health sector stated:

"If you implement 100\% of the reformulation agenda, you probably do not have junk food any longer because you have to reduce sodium, sugar, and saturated fats. Having only one piece of the reformulation agenda is not going to work, it has to be much more comprehensive, and has to change the ingredients... It is very difficult to improve junk foods." (Public Health Respondent)

Another limitation is the potential for mal-substitution or replacing one harmful ingredient with another. This is an especially large risk with highly processed foods where the ingredients used in substitution are also likely to be highly processed, industrial ingredients to fill the same roles as the ones removed and potentially with health impacts that are not yet known. An example of this was the push to remove fat and replace it with added sugar, as discussed above (Campbell et al. 2019; Scrinis and Monteiro 2018; Scrinis 2016; Lawrence 2004). Another example was the later push to remove saturated fats and replace them with trans fats, which were later found to have much worse health impacts and are still being removed from foods today. Some of these trans fats are being removed by replacing partially hydrogenated oils with those that are fully hydrogenated and inter-esterified, with unknown health impacts (Campbell et al. 2019; Scrinis and Monteiro 2018; Scrinis 2016).

While reformulation has been described as a win-win (i.e., a win for both public health and the food industry) by many, others have questioned or disputed this. In one interview with an academic, they stated that there was no win-win and argued that reformulation allows the food industry to position themselves as though they are working on the issue and taking adequate action despite their efforts being ineffective. They argue that this is more dangerous than doing nothing at all, stating,

"[Reformulation] leads to delayed action, policy inertia, and massive halo effects of so-called socially responsible firms going out and apparently voluntarily doing something that is 
making a difference. The disaster comes from a little bit of difference. From the psychological reasons I have just outlined. Action has to be reframed in policy making because a little bit of action is more dangerous than inaction... and in actual fact, all you are doing is propagating a myth that something effective is being done when nothing effective is being done. And the risks are huge." (Academic Respondent)

Additionally, this interview discussed some of the negative public health impacts that can result from reformulation. They describe licensing effects, wherein consumers think they are making a healthy choice by eating a reformulated product and then reward themselves by eating more of it or eating other unhealthy foods. Additionally, there can be a distal or vicarious licensing effect, wherein consumers see reformulated products offered by a company or on a menu and thus feel entitled to choose something less healthy from that company or menu. Additionally, there is calorie underestimation bias: when consumers see that a food has been reformulated, think it has fewer calories, and thus consume more of it. Another interview with an academic acknowledged the potential benefits of reformulation but argued there was still the need for larger dietary change, stating,

"In the intermediate, where we are, reformulation is a positive thing, we need to start shifting people away from eating loads of sugar and fat but it is not getting us on the pathway towards the large dietary shifts that we need both for health and for sustainability reasons." (Academic Respondent)

\section{CHALLENGES AND OPPORTUNITIES FOR REFORMULATION}

\section{SUPPLY CHALLENGES AND OPPORTUNITIES}

\section{The necessity of certain ingredients}

Reformulation poses many challenges for food companies to reduce or remove ingredients or nutrients from their products. It can be difficult to find acceptable replacements, and the process of finding new raw materials to incorporate into production must consider the entire value chain and its many actors.

For highly processed foods, each ingredient has a purpose, or more commonly several purposes, making it difficult to just reduce or remove something. Salt adds flavour but is also a preservative that has an important role in shelf-life and food safety. Salt is also critical for how dough handles while making bread (Munday and Bagley 2017). One interviewer described this, stating,

"It is really hard to find a single ingredient like salt that has all that same functionality, which really raises the complexity of what the solution is [for its replacement] and there is a lack of tools. You need microbial control, you need to think about what it does to the texture, 
changing proteins so you retain more moisture, it gives you that desired juiciness, tenderness that you are looking for in a piece of meat. And then really it is the taste and flavour enhancement." (Industry Respondent)

Similar to salt, sugar also serves many functions in food besides adding sweetness, from texture to bulk as well as preservation and others.

\begin{abstract}
"We think of sugar as just the thing that makes our beverages and food taste more sugary, but in reality, when you look at the functionality of sugar - for example, in foods it adds, among other things, desired texture. It controls the growth of yeast and mould in baked goods. It prolongs shelf-life in some preparations by multiple mechanisms. It improves the way proteins are worked into these preparations. It aids with the fermentation in baked goods. And if you look at the beverage side of things - so it not only adds the desired sweetness, but it also contributes mouthfeel and viscosity, shelf stability, and controls the crystallisation in frozen slushes. It is important in the development of certain caramelisation processes. It is crucial for those products in our portfolio that have to do with fermentation." (Industry Respondent)
\end{abstract}

Fats are also very important for appearance and texture, and different fats act differently.

One interview with industry described several reformulation failures that came from trying to remove ingredients. They described how reducing salt in hot dogs left them liquid in the centre and reducing salt in cheese prevented it from melting in grilled cheese or on cheeseburgers. They also described trying to remove trans and saturated fats from crackers: due to the way the crackers were packaged and stored on the shelf, liquid fats would run into the lower third of the cracker, leaving this part soggy with excess fat while the top third became dry and crumbled.

Ingredients need to be replaced in a way that maintains the food product's characteristics, such as appearance, taste, texture, and shelf-life as well as food safety (Food Drink Federation 2019; Van Gunst et al. 2018; Gibson et al. 2017; Buttriss 2013; Komitopoulou and Gibbs 2012). One interview with industry discussed these challenges, stating,

"I would not call it a lack of resistance as much as it is a lack of tools, so ultimately the measurement of success is whether or not the consumers are going to embrace it and go back and repeat purchases. There are big criteria, certain expectations within the consumers' mind, and if you do not get them right, if the taste is not quite there, the texture is off, the shelf-life,

if all of a sudden because you are removing certain ingredients, you are getting increased waste because they have to dispose of their food, which could have a potential economic impact on consumers personally. There are not good tools that can actually function and replace a lot of these ingredients." (Industry Respondent) 
The flavour of salt can be replaced using potassium chloride, but it has a slightly bitter taste that is unfavourable at higher levels, and consumers may be displeased by an unfamiliar ingredient on the label (Buttriss 2013). One interviewer mentioned the potential of using potassium chloride, stating,

"The best and closest single ingredient to salt is potassium chloride because it behaves a lot like salt in microbial management, it does a lot with the protein modification. The one area that it lacks, which is the most critical to consumers, is the taste, it is not as salty, it does not enhance flavours the same way." (Industry Respondent)

The sweetness of sugar can be replaced with non-nutritive sweeteners such as acesulfame-K, aspartame, neotame, saccharin, sucralose, and steviol glycosides, but given the minute quantities needed due to their sweetening potencies, they do not have the same properties as sugar with regards to texture and bulk. And again, consumers may not accept these ingredients, especially as most are artificial (Gibson et al. 2017). In an interview with an academic, they discussed the challenges with using non-nutritive sweeteners, stating,

"I think the biggest challenge has been and will continue to be that removing sugar is really hard for public perception, artificial sweeteners are not favourable for a lot of people, they do not have the same physical properties in the products. I really dislike the taste of them, so I would rather you not reformulate my products to have artificial sweeteners in them. So, I think there is a big challenge there." (Academic Respondent)

Additionally, the evidence on the health impacts and efficacy of non-nutritive sweeteners has been inconsistent. One review that looked at randomised controlled trials (RCTs) and prospective cohort studies found that the RCTs showed no benefit of non-nutritive sweeteners while the prospective studies showed an association with increased weight and waist circumference and higher incidence of hypertension, type 2 diabetes, and cardiovascular events (Azad et al. 2017). Other studies and reviews have also found no or adverse impacts (Brown et al. 2010; Reid et al. 2016; Lohner, Toews, and Meerpohl 2017; Toews et al 2019). Yet other studies have shown benefits on weight management and glycemia (Rogers et al 2016; Nichol et al 2018)—however, at least one of the study authors has ties to industry. Furthermore, a review by Mandrioli et al. concluded that studies on nonnutritive sweeteners with financial conflicts of interest were more likely to have favourable results and conclusions (Mandrioli et al. 2016). Other possible reasons for the inconsistent results across studies include study design, quality, and comparator (i.e. nothing, placebo, or sugar) (Mela et al. 2020). More high-quality research is needed.

\section{Consumer desire for clean labels}

Some fats can be replaced with emulsifiers and other additives, but consumers are increasingly rejecting these due to a desire for clean labels, which are labels with fewer 
ingredients and few to no artificial ingredients with which consumers are unfamiliar. One interview with industry brought up this challenge, stating,

"We have some examples of that in our Brazil business where the level of saturated fat has been significantly reduced between 25 and $50 \%$ or more in bakery products and around $30 \%$ in ice creams. But in order to get sufficient structure, which is what you normally get from saturated fats, lipid structuring has to be created by introducing emulsifiers. So, you get to lower levels of saturates, which is a good thing, but you have to add emulsifiers, and if you have really strong requirements for clean labels, that would not be an acceptable solution. And I think this seems to work well in Brazil, but I think in Europe it will be a less desirable solution because there is more focus on the label at this time." (Industry Respondent)

This consumer desire for clean labels, free of artificial ingredients, limits food producers' options for substitutions (Van Gunst et al. 2018). It is critical to understand what consumes will accept in these substitutions, as was discussed in one interview with industry,

"One other piece of work we do is really trying to understand consumer insights and perceptions of certain ingredients to try to help our customers, and help us in our innovation pipeline to really understand those ingredients, how you label them, what they look like, and really what consumer perception is going to be about them. If you can tackle the substitutions for an ingredient, if you can tackle the operations piece of it, the actual production of food, having that consumer insight piece can really complete that holistic approach and ensure you can bring a true solution to our customers." (Industry Respondent)

\section{Composition and serving sizes of certain food products}

Additionally, the composition of some food products may be dictated by legislation, such as for certain cheeses, preventing reformulation past a certain point unless legislation is changed (Buttriss 2013; Van Raaij et al. 2008). Several of the interviews with industry discussed being limited by legislation on the compositions of foods. For example, yogurt must contain a certain percent of dairy, which limits the amount of fruit or nuts that can be added. Similarly, ice cream must contain at least $10 \%$ dairy fat in the United States, limiting reformulation.

Nutrient profiling is a tool that ranks and classifies foods based on their nutrient composition (WHO 2011). Companies that reformulate foods struggle with reference values for the amount of specific foods consumed versus the serving size. Spieldenner and van der Horst (2018) make a call for clear, transparent, realistic, and binding targets for critical ingredients across food categories. Such targets and standards, in combination with mandatory portion or serving sizes reflecting true consumption patterns, will make products easily comparable for the consumer and subsequently drive more reformulation efforts.

\section{Limitations of technology}


Food technology is often a challenge, as the technology may not exist or may be economically unfeasible to lower salt, added sugar, and saturated and trans fats levels beyond a certain point (Food Drink Federation 2019; Van Gunst et al. 2018; Gibson et al. 2017; Buttriss 2013; Komitopoulou and Gibbs 2012). Additionally, there are even larger challenges in knowledge and technology for smaller companies. One researcher pointed out the importance of sharing knowledge,

"The mechanism is to share knowledge about reformulation of critical fats, that is one of the commitments we requested from industry. We said, 'Okay, you commit to limit trans fats, but you also commit to share your knowledge with small and medium enterprises.' They agreed to do this." (Public Health Respondent)

However, technology is always emerging and improving to make reformulation easier and more affordable. For example, food scientists can now change salt crystal size and shape to reduce salt while maintaining the same flavour. Scientists can also use high-pressure homogenisation to reduce fat in ice cream without losing smoothness or creating iciness (Buttriss 2013). As new technologies develop and decrease in cost, reformulation will become easier and faster.

\section{Sustainable goals and practices}

One of the most important emerging challenges for reformulation is environmental sustainability. In the face of the climate crisis, sustainability is a new focus. Many food companies have their own sustainability goals and discussed using reformulation as a way to meet these, with sustainability being another reason behind reformulation. One interview with industry discussed considering the large environmental impacts of their products, stating, "These are food systems wide changes that we have to think of from end to end, from the crops that we use to create our products all the way to the environmental impact in sustainability terms." (Industry Respondent)

Another interview with a researcher acknowledged the growing discussions around sustainability but was more critical of the food industry, arguing that they were really focused on only a few things, stating, "They are concerned about their main issues, coffee, potatoes, beef, and tomatoes. They care about those four things. They do not care about much of anything else at this point." (Academic Respondent)

There is a large risk that the food industry will misdirect the focus and derail more meaningful action on sustainability by 'greenwashing' (i.e., providing misleading information or marketing about how environmentally friendly or sustainable a company's products or practices are) unsustainable practices. 


\section{DEMAND CHALLENGES AND OPPORTUNITIES}

\section{Consumer acceptance of new products}

The largest challenge of reformulation cited by many food companies is concern over consumer acceptance (Van Gunst et al. 2018). In one interview, it was stated that reformulated products must be indistinguishable from the original, not just equally preferable.

"Consumer acceptance is sometimes a barrier, since we have consumers that are acclimated to certain tastes or may have an aversion to the other ingredients that we might use in order to remove sugar, so it can be a double-edged sword there." (Industry Respondent)

One interview with industry discussed how immediate the consumer reaction is to reformulation, stating, "Loyal consumers will not like it and potentially not buy it or phone up. We know within hours of new products landing on shelves because we get consumer complaints." (Industry Respondent)

Another interview with industry discussed the impacts of failing to maintain the taste, texture, or other characteristics of a food and how quickly consumers will switch to another product, stating,

"We have faced some failures of reformulations of products that were not accepted by consumers. We did all the reformulation work, we put the product on the market, and then we had very big disappointments with very sharp decreases of sales by $30 \%$ in three weeks that were obliging you to go back to the previous formula." (Industry Respondent)

Consumers are accustomed to the levels of salt, sugar, and fat in packaged foods, and even more specifically in their favourite brands and products. Additionally, not only do these ingredients influence the taste and texture, they can also change even more subtle factors like the weight of the product. One interview with industry stated,

"When you take that much sugar out, all of a sudden, the weight of the cereal in the carton is not the same, people really pick up on that, and they think we are trying to trick them. So, you have to put something in its place for not only bowl life, appearance, and texture, but also for the consumer's perception of the weight of the food." (Industry Respondent)

One approach to reformulation, stealth reformulation, has been slowly and incrementally decreasing the amount of an ingredient. This avoids a large change in taste and gives consumers time for their taste to adapt (Van Raaij et al. 2008). Several of the interviews with 
industry mentioned this as being more effective in avoiding upsetting consumers. One interview with industry stated,

"If we have to remove two grams, or $2 \%$, of sugar from our product, we start by removing one gram because we know that is quite invisible for consumers, but more than one gram and they notice it. So, we start by removing one gram and let the consumer get used to that, and then we remove one more gram, that is more acceptable for consumers." (Industry Respondent)

This approach involves not marketing these changes to consumers, as even sometimes just an indication of a change on the packaging can be enough to upset consumers. One interview with industry described this, stating,

\begin{abstract}
"We committed to removing trans fats and making a change to more sustainable oils. They were switching to sunflower oil and they put a sunflower on the bag, and consumers actually had a very negative reaction because they felt like 'You are changing my beloved chips,' but the interesting thing was that we just changed the packaging back and stopped talking about the change, and that fixed the issue, so sometimes it is just a perception issue. Even if we just make a package or a labelling change and we do not actually change the product, consumers will sometimes complain and have a negative perception." (Industry Respondent)
\end{abstract}

This has been successfully used for the reduction of salt. For example, in the United Kingdom, the food industry slowly reduced salt over time. Salt in bread decreased by $40 \%$ (Buttriss 2013) and in breakfast cereal by 60\%, but these reductions occurred over 20 years (Food Drink Federation 2019). Several of the interviews stated that while salt really requires this slow, stepwise reduction, it is easier to reduce sugar faster as there are usually other flavours that you can change, such as reducing sugar but making the product more chocolatey.

Several of the interviews with industry explained that it was easier to make new products with lower levels of salt, sugar, and unhealthy fats than to change the levels in existing products; however, there are different challenges with new products.

"Understanding where [reformulation] stops and where innovation plays a role, and for each brand you have a role for both, and typically that is how you do what we call brand planning and strategic planning. So, you would ask what your reformulation pipeline looks like, and then what does your innovation pipeline look like, and if you are starting from scratch it is much, much easier. If you look at our new recipes around the world, they are much lower in sugar, they tend to have the cleanest labels, they have lots of fortification. But launching a new brand or launching a new food is very difficult and you do not have the volume, if you think about the millions of boxes that we sell of an established brand versus something that is 
new to the market, it takes quite a while to pick up speed, but there is a role for that for sure." (Industry Respondent)

Additionally, if reformulated or new products are not accepted and consumed by consumers, that limits their impact. One interview with a researcher stated,

"Any improvements in the nutrient profile of the product portfolio need to be tracked with respect to product sales. You cannot say, 'Oh, we have this product,' like McDonald's says, 'We have a salad.' Well, the salad does not sell, you sell 1,000 hamburgers and two salads. Did that move the needle? No. You have to give a weighted average to show that the healthy products are actually selling, so it is a business proposition as opposed to just a feel-good exercise." (Academic Respondent)

\section{Cost of reformulation}

Reformulation is also very expensive, with one estimate placing the cost between 5,000 and four million USD per product. One study looked at reformulation of foods aimed at children and found that they were three to twelve cents more expensive per serving (Muth et al. 2019). This makes it difficult for the food industry to reformulate without increasing prices and losing consumers. One interview with industry discussed these challenges, stating, "It does cost. It definitely costs, because you think about the resourcing of people to do this, nutritionists, food technologists, science and technology teams. It might be a matter of sourcing other ingredients, we might be looking at the environmental side of it too." (Industry Respondent)

\section{Emerging demand trends}

Despite the challenges discussed above, many consumers are now demanding healthier food products and are actively looking at labels and other health information as well as looking at the sustainability of the foods they are purchasing. A 2018 survey of almost 1,600 consumers in the United States found that 93\% want to eat healthy at least some of the time and $63 \%$ most or all of the time. The number of consumers interested in almost a dozen health claims had increased by $20 \%$ since 2016 . The survey also found that consumers were interested in all-natural foods, with much higher demand for foods without artificial ingredients.

Additionally, up to $70 \%$ of consumers said they were willing to pay a premium for foods that were all-natural, ethical, enhanced, or had been reformulated to have lower levels of negative ingredients or nutrients, up 10\% from 2016 (L.E.K. 2018). This gives food companies a chance to gain new customers as well as stay ahead or join with trends (Van Gunst et al. 2018).

Additionally, as environmental sustainability becomes a more pressing issue, there is an increased demand for plant-based proteins, and there is a shift from animal to plant protein in high-income countries. This includes plant-based burgers and other meat alternatives and plant-based milks, such as those made form legumes, grains, and nuts. One interview with a researcher mentioned this, stating, "in the rich countries it's going from animal to plant, but 
the overwhelming global trend is from plant to animal, of course. So, the protein transition is actually two-phased." (Academic Respondent)

One interview with industry discussed their actions to meet this increasing demand, stating,

"That has stimulated us as a company to really look at the innovation side, and we are starting to look at more plant-based products. We have a gourmet plant burger, we have plant-based dairy analogues." (Industry Respondent)

Another interview with industry also discussed this, stating,

"We have a diversified portfolio of plant-based products that have lower carbon footprints and deliver essential fatty acids and vitamins, that are fortified, fortifying in fact. But the challenge is in the processing. For example, with [our plant-based burger], we are able to provide good taste for this vegan burger but if you look at the composition and the list of ingredients and how the product has been made, [it is very processed]. But the choice is still very sexy for some consumers." (Industry Respondent)

Some of these are highly processed, and while they may be a win for sustainability, they may need additional reformulation to be a win for public health. One interview discussed the amount of processing in these products, stating, "Beyond Meat and the Impossible Burger are very highly processed foods and yet people are falling all over themselves, saying 'This is wonderful. It is plant protein.'" (Industry Respondent)

Many of the interviews with industry discussed their internal commitments to sustainability, with one interview discussing the methods and tools for evaluating the sustainability of their products, stating,

"The tool determines areas of the value chain that the project may directly impact from agriculture, raw materials, ingredients, food processing, packaging, and waste, and if an environmental risk or benefit is identified, the new product can be compared to the old, and then we use an eco-design screen tool called Ecodex, which we have been using for the last six years, to look at a lifecycle analysis. It identifies five environmental indicators, so that we can then understand any trade-offs between climate and water" (Industry Respondent)

\section{RECOMMENDATIONS \& CONCLUSION}

Reformulation has the potential to improve diets and nutrition and make large impacts on public health by decreasing salt, added sugar, saturated and trans fats, and energy density intakes. There are also benefits to reformulation to enhance the nutritional content of foods by adding nutrients or health-promoting ingredients. An emerging yet nascent space in the 
reformulation world is to reformulate not only for health but also for environmental sustainability. However, in order for reformulation to have widespread positive effects, it needs to be mandatory as well as part of a comprehensive government-led strategy that also includes mandatory labelling, taxes, and subsidies. Mandatory reformulation increases the potential benefits, as it can set more ambitious and comprehensive targets that can be enforced and it applies to all foods from all companies.

Despite its promise, reformulation is not a panacea for diets and nutrition. Even with mandatory reformulation, there may still be calorie underestimation bias. Additionally, reformulation will not lead to the necessary dietary shift towards more fruits, vegetables, whole grains, legumes, and some animal-source foods for some nutritionally vulnerable populations.

There are many negative and positive incentives that drive reformulation, including warning labels, taxes, mandates, and consumer preferences and demands. While reformulation can be voluntary, reformulation to remove unhealthy ingredients such as salt, sugar, and unhealthy fats should be government mandated with clear, transparent and direct targets that are in the interest of public health. There should also be independent monitoring and evaluation and meaningful repercussions for missed targets by a larger body such as the WHO. The food industry should be involved in implementing reformulation policies but not in their design (Campbell et al. 2019; Vandevijvere and Vanderlee 2019; Scrinis and Monteiro 2018).

Challenges, from both food supply and consumer demand perspectives, should not be underestimated. Reformulating foods is not an easy, inexpensive task for food companies. Simply reducing or removing salt or sugar can have significant ramifications for the taste, architecture, shelf-life, and consistency of foods. Meeting government mandates can be challenging and, sometimes, impossible for companies to reach while still aligning to consumers' expectations for their favourite brands. There are also consumer demand issues. While consumers like their brands, demands are also changing. More and more, consumers care about clean labels, environmental sustainability, and how their foods are sourced.

While the challenges are significant, so are the opportunities. Reformulation could be a winwin for both public health and economic growth. The growing interest of consumers in the healthfulness of the foods they consume and where and how food is sourced, considering environmental and trade aspects, will drive reformulation for companies to meet that demand. This will serve to further secure a thriving consumer base. Taxes, front-of-pack warning labels, and mandates will only further drive the need to reformulate.

Reformulation should not be seen and done in isolation but instead should be part of a comprehensive strategy to improve diet quality that also includes mandatory labelling, taxes and subsidies, and other government action (Buttriss 2013; Leroy et al. 2016). Reformulation can contribute to reducing dietary intake of salt, sugar, and unhealthy fats from highly processed foods. While reformulation has potential health benefits, it will not solve the issues with diet quality that exist across the world. Reformulation will not create the larger shift in diets towards unprocessed and minimally processed foods that is needed for nutrition and health. For this to occur, policies and actions are needed that improve the availability, 
affordability, and demand for all types of nutritious foods, including fresh unprocessed foods such as fruits, vegetables, nuts and seeds, whole grains, legumes and minimally processed foods (Scrinis and Monteiro 2018; Baker and Friel 2014). Nonetheless, enhancing the nutritional value and limiting the unhealthful components of processed foods through reformulation may have an important role to play in our future food system but it must be done alongside larger scale efforts to improve access to healthy, diverse and safe diets. 


\section{REFERENCES}

Afshin, A., Sur, P.J., Fay, K.A., Cornaby, L., Ferrara, G., Salama, J.S., Mullany, E.C., Abate, K.H., Abbafati, C., Abebe, Z. and Afarideh, M., 2019. Health effects of dietary risks in 195 countries, 1990-2017: a systematic analysis for the Global Burden of Disease Study 2017. The Lancet, 393(10184), pp.1958-1972.

Augustin, M.A., Riley, M., Stockmann, R., Bennett, L., Kahl, A., Lockett, T., Osmond, M., Sanguansri, P., Stonehouse, W., Zajac, I. and Cobiac, L., 2016. Role of food processing in food and nutrition security. Trends in Food Science \& Technology, 56, pp.115-125.

Azad, M.B., Abou-Setta, A.M., Chauhan, B.F., Rabbani, R., Lys, J., Copstein, L., Mann, A., Jeyaraman, M.M., Reid, A.E., Fiander, M. and MacKay, D.S., 2017. Nonnutritive sweeteners and cardiometabolic health: a systematic review and meta-analysis of randomized controlled trials and prospective cohort studies. Cmaj, 189(28), pp.E929E939.

Baker, P. and Friel, S., 2014. Processed foods and the nutrition transition: evidence from Asia. Obesity reviews, 15(7), pp.564-577.

Baker, Phillip, and Sharon Friel. 2016. Food Systems Transformations, Ultra-Processed Food Markets and the Nutrition Transition in Asia." Globalization and Health. https://doi.org/Food Systems Transformations, Ultra-Processed Food Markets and the Nutrition Transition in Asia." Globalization and Health. https://doi.org/10.1186/s12992-016-0223-3.

Balarajan, Yarlini, and Michael R. Reich. 2016. "Political Economy Challenges in Nutrition." Globalization and Health 12 (1): 70.

Bhagwati, J., Bourguignon, F., Kydland, F.E., Mundell, R., North, D.C., Schelling, T., Smith, V.L. and Stokey, N., 2017. Copenhagen Consensus 2008-Results.

Bogard, J.R., Hother, A.L., Saha, M., Bose, S., Kabir, H., Marks, G.C. and Thilsted, S.H., 2015. Inclusion of small indigenous fish improves nutritional quality during the first 1000 days. Food and nutrition bulletin, 36(3), pp.276-289.

Brown, L., Rosner, B., Willett, W.W. and Sacks, F.M., 1999. Cholesterol-lowering effects of dietary fiber: a meta-analysis. The American journal of clinical nutrition, 69(1), pp.3042.

Brown, R.J., De Banate, M.A. and Rother, K.I., 2010. Artificial sweeteners: a systematic review of metabolic effects in youth. International Journal of Pediatric Obesity, 5(4), pp.305312.

Buttriss, J.L., 2013. Food reformulation: the challenges to the food industry. Proceedings of the Nutrition Society, 72(1), pp.61-69.

Campbell, N., Reilly, K., Claudy, M., and Finucane, F., 2019. Reformulating reformulation: A technical appraisal and policy context for the 2019 FDI report on the impact of ultraprocessed food reformulation in Ireland. Version 2. 
Carpentier, F.R.D., Correa, T., Reyes, M. and Taillie, L.S., 2020. Evaluating the impact of Chile's marketing regulation of unhealthy foods and beverages: pre-school and adolescent children's changes in exposure to food advertising on television. Public health nutrition, 23(4), pp.747-755.

Cediel, G., Reyes, M., da Costa Louzada, M.L., Steele, E.M., Monteiro, C.A., Corvalán, C. and Uauy, R., 2018. Ultra-processed foods and added sugars in the Chilean diet (2010). Public health nutrition, 21(1), pp.125-133.

Consumer Good Food. 2019. https://www.theconsumergoodsforum.com/wpcontent/uploads/2019/03/2019-CGF-Health-Wellness-Progress-Report-DeloitteWeb-

Teaser.pdf?utm source=digitalteaser\&utm campaign=2019HW ProgressReport

Correa, T., Fierro, C., Reyes, M., Carpentier, F.R.D., Taillie, L.S. and Corvalan, C., 2019. Responses to the Chilean law of food labeling and advertising: exploring knowledge, perceptions and behaviors of mothers of young children. International Journal of Behavioral Nutrition and Physical Activity, 16(1), p.21.

Das, J.K., Salam, R.A., Kumar, R. and Bhutta, Z.A., 2019. Micronutrients food fortification and its impact on woman and child health: a systematic.

DiNicolantonio, J.J., Lucan, S.C. and O'Keefe, J.H., 2016. The evidence for saturated fat and for sugar related to coronary heart disease. Progress in cardiovascular diseases, 58(5), pp.464-472.

Downs, S.M., Bloem, M.Z., Zheng, M., Catterall, E., Thomas, B., Veerman, L. and Wu, J.H., 2017. The impact of policies to reduce trans fat consumption: A systematic review of the evidence. Current developments in nutrition, 1(12), pp.cdn-117.

Downs, S.M., Thow, A.M. and Leeder, S.R., 2013. The effectiveness of policies for reducing dietary trans fat: a systematic review of the evidence. Bulletin of the World Health Organization, 91, pp.262-269h.

Drewnowski, A., 2017. Uses of nutrient profiling to address public health needs: from regulation to reformulation. Proceedings of the Nutrition Society, 76(3), pp.220-229.

Dunford, E., and Taylor, F. 2018. Report on the comparative nutritional profile of food and beverage products marketed by the 21 largest global companies in 9 countries. Access to Nutrition Foundation and the George Institute for Global Health. https://accesstonutrition.org/app/uploads/2020/02/Gl Global-Index TGl-productprofile Report 2018.pdfAccess to Nutrition Index. 2018. Access to Nutrition Index Global Index 2018. Version 2.

European Commission. 2012. Survey on Members States' implementation of the EU Salt Reduction Framework.

Fanzo, J., Hawkes, C., Udomkesmalee, E., Afshin, A., Allemandi, L., Assery, O., Baker, P., Battersby, J., Bhutta, Z., Chen, K. and Corvalan, C., 2018. 2018 Global Nutrition Report: Shining a light to spur action on nutrition. 
Fardet, A., 2018. Characterization of the degree of food processing in relation with its health potential and effects. In Advances in food and nutrition research (Vol. 85, pp. 79129). Academic Press.

Federici, C., Detzel, P., Petracca, F., Dainelli, L. and Fattore, G., 2019. The impact of food reformulation on nutrient intakes and health, a systematic review of modelling studies. BMC Nutrition, 5(1), p.2.

Fiolet, T., Srour, B., Sellem, L., Kesse-Guyot, E., Allès, B., Méjean, C., Deschasaux, M., Fassier, P., Latino-Martel, P., Beslay, M. and Hercberg, S., 2018. Consumption of ultra-processed foods and cancer risk: results from NutriNet-Santé prospective cohort. BMJ, 360, p.k322.

Food Drink Ireland. 2017. The evolution of food and drink in Ireland 2005-2007: Reformulation and innovation supporting Irish diets.

Friesen, V.M., Mbuya, M.N., Aaron, G.J., Pachón, H., Adegoke, O., Noor, R.A., Swart, R., Kaaya, A., Wieringa, F.T. and Neufeld, L.M., 2020. Fortified Foods Are Major Contributors to Apparent Intakes of Vitamin A and lodine, but Not Iron, in Diets of Women of Reproductive Age in 4 African Countries. The Journal of Nutrition.

Gibney, M.J., Forde, C.G., Mullally, D. and Gibney, E.R., 2017. Ultra-processed foods in human health: a critical appraisal. The American journal of clinical nutrition, 106(3), pp.717-724.

Gibson, S., Ashwell, M., Arthur, J., Bagley, L., Lennox, A., Rogers, P.J. and Stanner, S., 2017. What can the food and drink industry do to help achieve the $5 \%$ free sugars goal? Perspectives in public health, 137(4), pp.237-247.

Goryakin, Y., Aldea, A., Lerouge, A. and Guillemette, Y., 2019. Special focus: The health and economic impact of food reformulation.

Gressier, M., Privet, L., Mathias, K.C., Vlassopoulos, A., Vieux, F. and Masset, G., 2017. Modeled dietary impact of industry-wide food and beverage reformulations in the United States and France. The American journal of clinical nutrition, 106(1), pp.225232.

Griffith, R., O'Connell, M. and Smith, K., 2017. The importance of product reformulation versus consumer choice in improving diet quality. Economica, 84(333), pp.34-53.

Hall, K.D., Ayuketah, A., Brychta, R., Cai, H., Cassimatis, T., Chen, K.Y., Chung, S.T., Costa, E., Courville, A., Darcey, V. and Fletcher, L.A., 2019. Ultra-processed diets cause excess calorie intake and weight gain: an inpatient randomized controlled trial of ad libitum food intake. Cell metabolism.

Hashem, K.M., He, F.J. and MacGregor, G.A., 2019. Effects of product reformulation on sugar intake and health-a systematic review and meta-analysis. Nutrition reviews, 77(3), pp.181-196.

Heaton, T. 2019. How Nepal became obsessed with instant noodles and why it's here to stay. The Kathmandu Post.

HLPE 2017. Food Systems for Food and Nutrition. CFS, Rome, Italy. 
Huang, Y., Kypridemos, C., Liu, J., Lee, Y., Pearson-Stuttard, J., Collins, B., Bandosz, P., Capewell, S., Whitsel, L., Wilde, P. and Mozaffarian, D., 2019. Cost-Effectiveness of the US Food and Drug Administration Added Sugar Labeling Policy for Improving Diet and Health. Circulation, 139(23), pp.2613-2624.

IGD. 2019. Healthier product reformulation in India: Consumer and company research on progress and priorities.

Jaenke, R., Barzi, F., McMahon, E., Webster, J. and Brimblecombe, J., 2017. Consumer acceptance of reformulated food products: A systematic review and meta-analysis of salt-reduced foods. Critical reviews in food science and nutrition, 57(16), pp.33573372.

Jones, J.M., 2019. Food processing: criteria for dietary guidance and public health? Proceedings of the Nutrition Society, 78(1), pp.4-18.

Kaldor, J.C., 2017. What's wrong with mandatory nutrient limits? Rethinking dietary freedom, free markets and food reformulation. Public Health Ethics, 11(1), pp.54-68.

Kanter, R., Reyes, M., Swinburn, B., Vandevijvere, S. and Corvalán, C., 2019a. The food supply prior to the implementation of the Chilean Law of Food Labeling and Advertising. Nutrients, 11(1), p.52.

Kanter, R., Reyes, M., Vandevijvere, S., Swinburn, B. and Corvalán, C., 2019b. Anticipatory effects of the implementation of the Chilean Law of Food Labeling and Advertising on food and beverage product reformulation. Obesity Reviews.

Keenan, J.M., Pins, J.J., Frazel, C., Moran, A. and Turnquist, L., 2002. Oat ingestion reduces systolic and diastolic blood pressure in patients with mild or borderline hypertension: a pilot trial. J Fam Pract, 51(4), p.369.

Klassen-Wigger, P., Geraets, M., Messier, M.C., Detzel, P., Lenoble, H.P. and Barclay, D.V., 2018. Micronutrient Fortification of Bouillon Cubes in Central and West Africa. In Food Fortification in a Globalized World (pp. 363-372). Academic Press.

Knai, C., James, L., Petticrew, M., Eastmure, E., Durand, M.A. and Mays, N., 2017. An evaluation of a public-private partnership to reduce artificial trans fatty acids in England, 2011-16. The European Journal of Public Health, 27(4), pp.605-608.

Knorr, D. and Watzke, H., 2019. Food Processing at a Crossroad. Frontiers in nutrition, 6.

Komitopoulou, E. and Gibbs, P.A., The Pitfalls of Product Reformulation and How to Avoid Them.

Kumar, S., Anukiruthika, T., Dutta, S., Kashyap, A.V., Moses, J.A. and Anandharamakrishnan, C., 2020. Iron deficiency anemia: A comprehensive review on iron absorption, bioavailability and emerging food fortification approaches. Trends in Food Science \& Technology.

L.E.K., 2018. Consumer health claims 3.0: The next generation of mindful food consumption. 20(51). https://www.lek.com/insights/ei/next-generation-mindful-food-consumption 
Lairon, D., Arnault, N., Bertrais, S., Planells, R., Clero, E., Hercberg, S. and Boutron-Ruault, M.C., 2005. Dietary fiber intake and risk factors for cardiovascular disease in French adults. The American journal of clinical nutrition, 82(6), pp.1185-1194.

Lawrence, M.A., Baker, P.I., Pulker, C.E. and Pollard, C.M., 2019. Sustainable, resilient food systems for healthy diets: The transformation agenda. Public health nutrition, 22(16), pp.2916-2920.

Leroy, P., Requillart, V., Soler, L.G. and Enderli, G., 2016. An assessment of the potential health impacts of food reformulation. European journal of clinical nutrition, 70(6), p.694.

Leslie, I. 2016. The sugar conspiracy. The Guardian.

Liu, S., Stampfer, M.J., Hu, F.B., Giovannucci, E., Rimm, E., Manson, J.E., Hennekens, C.H. and Willett, W.C., 1999. Whole-grain consumption and risk of coronary heart disease: results from the Nurses' Health Study. The American journal of clinical nutrition, 70(3), pp.412-419.

Lohner, S., Toews, I. and Meerpohl, J.J., 2017. Health outcomes of non-nutritive sweeteners: analysis of the research landscape. Nutrition journal, 16(1), p.55.

Mantilla Herrera, A., Crino, M., Erskine, H., Sacks, G., Ananthapavan, J., Mhurchu, C. and Lee, Y., 2018. Cost-effectiveness of product reformulation in response to the Health Star Rating food labelling system in Australia. Nutrients, 10(5), p.614.

Markets and Markets, 2019. Probiotics Market by Application (Functional Food and Beverages [Dairy Products, Non-dairy Beverages, Infant Formula, Cereals], Dietary Supplements, Feed), Ingredient (Bacteria, Yeast), Form (Dry, Liquid), End User, and Region - Global Forecast to 2023.

Mandrioli, D., Kearns, C.E. and Bero, L.A., 2016. Relationship between research outcomes and risk of bias, study sponsorship, and author financial conflicts of interest in reviews of the effects of artificially sweetened beverages on weight outcomes: a systematic review of reviews. PloS one, 11(9), p.e0162198.

Martínez, E.S., Popkin, B.M., Swinburn, B. and Monteiro, C.A., 2017. The share of ultraprocessed foods and the overall nutritional quality of diets in the US: evidence from a nationally representative cross-sectional study. Population health metrics, 15(1), pp.66.

Mela, D.J., McLaughlin, J. and Rogers, P.J., 2020. Perspective: Standards for Research and Reporting on Low-Energy ("Artificial") Sweeteners. Advances in Nutrition, 11(3), pp.484-491.

Mendonça, R.D.D., Lopes, A.C.S., Pimenta, A.M., Gea, A., Martinez-Gonzalez, M.A. and BesRastrollo, M., 2017. Ultra-processed food consumption and the incidence of hypertension in a Mediterranean cohort: the Seguimiento Universidad de Navarra Project. American journal of hypertension, 30(4), pp.358-366. 
Mhurchu, C., Eyles, H. and Choi, Y.H., 2017. Effects of a voluntary front-of-pack nutrition labelling system on packaged food reformulation: The health star rating system in New Zealand. Nutrients, 9(8), p.918.

Monteiro, C.A., 2009. Nutrition and health. The issue is not food, nor nutrients, so much as processing. Public health nutrition, 12(5), pp.729-731.

Monteiro, C.A., Cannon, G., Levy, R.B., Moubarac, J.C., Jaime, P., Martins, A.P., Canella, D., Louzada, M. and Parra, D., 2016. NOVA. The star shines bright. World Nutrition, 7(13), pp.28-38.

Monteiro, C.A., Cannon, G., Levy, R.B., Moubarac, J.C., Louzada, M.L., Rauber, F., Khandpur, N., Cediel, G., Neri, D., Martinez-Steele, E. and Baraldi, L.G., 2019. Ultra-processed foods: what they are and how to identify them. Public health nutrition, 22(5), pp.936941.

Monteiro, C.A., Cannon, G., Moubarac, J.C., Levy, R.B., Louzada, M.L.C. and Jaime, P.C., 2018. The UN Decade of Nutrition, the NOVA food classification and the trouble with ultra-processing. Public Health Nutrition, 21(1), pp.5-17.

Monteiro, C.A., Moubarac, J.C., Levy, R.B., Canella, D.S., da Costa Louzada, M.L. and Cannon, G., 2018. Household availability of ultra-processed foods and obesity in nineteen European countries. Public Health Nutrition, 21(1), pp.18-26.

Montonen, J., Knekt, P., Järvinen, R., Aromaa, A. and Reunanen, A., 2003. Whole-grain and fiberfibre intake and the incidence of type 2 diabetes. The American journal of clinical nutrition, 77(3), pp.622-629.

Morrison, H., Meloncelli, N. and Pelly, F.E., 2019. Nutritional quality and reformulation of a selection of children's packaged foods available in Australian supermarkets: Has the Health Star Rating had an impact? Nutrition \& Dietetics, 76(3), pp.296-304.

Moubarac, J.C., Martins, A.P.B., Claro, R.M., Levy, R.B., Cannon, G. and Monteiro, C.A., 2013. Consumption of ultra-processed foods and likely impact on human health. Evidence from Canada. Public Health Nutrition, 16(12), pp.2240-2248.

Mozaffarian, D., Jacobson, M.F. and Greenstein, J.S., 2010. Food reformulations to reduce trans fatty acids. New England Journal of Medicine, 362(21), pp.2037-2039.

Mozaffarian, D., Katan, M.B., Ascherio, A., Stampfer, M.J. and Willett, W.C., 2006. Trans fatty acids and cardiovascular disease. New England Journal of Medicine, 354(15), pp.1601-1613.

Munday, H. and Bagley, L., 2017. The history of food reformulation. Food Science \& Technology, 31(3), pp.32-39.

Muth, M.K., Karns, S.A., Mancino, L. and Todd, J.E., 2019. How Much Can Product Reformulation Improve Diet Quality in Households with Children and Adolescents? Nutrients, 11(3), p.618.

N4G (Nutrition for Growth) Summit, 2020. Vision and Roadmap. Accessed January 18, 2020. https://nutritionforgrowth.org/wp-content/uploads/2019/12/Nutrition-for-Growth2020-Vision-and-Roadmap.pdf 
National Heart Foundation of Australia. 2012. Rapid review of the evidence: Effectiveness of food reformulation as a strategy to improve population health.

Neufeld, L.M. and Friesen, V.M., 2018. Impact evaluation of food fortification programs: review of methodological approaches used and opportunities to strengthen them. In Food Fortification in a Globalized World (pp. 305-315). Academic Press.

Nichol, A.D., Holle, M.J. and An, R., 2018. Glycemic impact of non-nutritive sweeteners: a systematic review and meta-analysis of randomized controlled trials. European Journal of Clinical Nutrition, 72(6), pp.796-804.

Poti, J.M., Mendez, M.A., Ng, S.W. and Popkin, B.M., 2015. Is the degree of food processing and convenience linked with the nutritional quality of foods purchased by US households? The American Journal of Clinical Nutrition, 101(6), pp.1251-1262.

Poudel, A. 2019. Nutritionist's resignation from Baliyo Nepal raises questions about the project's commitment to combating malnutrition. The Kathmandu Post.

Pries, A.M., Rehman, A.M., Filteau, S., Sharma, N., Upadhyay, A. and Ferguson, E.L., 2019. Unhealthy Snack Food and Beverage Consumption Is Associated with Lower Dietary Adequacy and Length-for-Age z-Scores among 12-23-Month-Olds in Kathmandu Valley, Nepal. The Journal of nutrition, 149(10), pp.1843-1851.

Rauber, F., Campagnolo, P.D.B., Hoffman, D.J. and Vitolo, M.R., 2015. Consumption of ultraprocessed food products and its effects on children's lipid profiles: a longitudinal study. Nutrition, Metabolism and Cardiovascular Diseases, 25(1), pp.116-122.

Reid, A.E., Chauhan, B.F., Rabbani, R., Lys, J., Copstein, L., Mann, A., Abou-Setta, A.M., Fiander, M., MacKay, D.S., McGavock, J. and Wicklow, B., 2016. Early exposure to nonnutritive sweeteners and long-term metabolic health: a systematic review. Pediatrics, 137(3), p.e20153603.

Rogers, P., 2015. Effects of low-energy sweeteners consumption on appetite and weight control. Annals of Nutrition and Metabolism, 67, pp.96-97.

Rubin R 2020. Backlash Over Meat Dietary Recommendations Raises Questions About Corporate Ties to Nutrition Scientists JAMA. doi:10.1001/jama.2019.21441

Schnabel, L., Buscail, C., Sabate, J.M., Bouchoucha, M., Kesse-Guyot, E., Allès, B., Touvier, M., Monteiro, C.A., Hercberg, S., Benamouzig, R. and Julia, C., 2018. Association between ultra-processed food consumption and functional gastrointestinal disorders: results from the French NutriNet-Santé Cohort. The American journal of gastroenterology, 113(8), p.1217.

Scott, C. and Nixon, L., 2018. The shift in framing of food and beverage product reformulation in the United States from 1980 to 2015. Critical public health, 28(5), pp.606-618.

Scott, C., Hawkins, B. and Knai, C., 2017. Food and beverage product reformulation as a corporate political strategy. Social science \& medicine, 172, pp.37-45.

Scrinis, G. and Monteiro, C.A., 2018. Ultra-processed foods and the limits of product reformulation. Public health nutrition, 21(1), pp.247-252. 
Scrinis, G., 2016. Reformulation, fortification and functionalization: Big Food corporations' nutritional engineering and marketing strategies. The Journal of Peasant Studies, 43(1), pp.17-37.

Spieldenner, J. and Van der Horst, K., 2018. Reformulating food products for improved nutrition: Or: How to improve processed foods quietly. Sight and Life Magazine, 31(1), pp.67-71.

Spiteri, M. and Soler, L.G., 2018. Food reformulation and nutritional quality of food consumption: an analysis based on households' panel data in France. European journal of clinical nutrition, 72(2), p.228.

Steele, E.M., Baraldi, L.G., da Costa Louzada, M.L., Moubarac, J.C., Mozaffarian, D. and Monteiro, C.A., 2016. Ultra-processed foods and added sugars in the US diet: evidence from a nationally representative cross-sectional study. BMJ open, 6(3), p.e009892.

Steffen, L.M., Jacobs Jr, D.R., Stevens, J., Shahar, E., Carithers, T. and Folsom, A.R., 2003. Associations of whole-grain, refined-grain, and fruit and vegetable consumption with risks of all-cause mortality and incident coronary artery disease and ischemic stroke: The Atherosclerosis Risk in Communities (ARIC) Study. The American journal of clinical nutrition, 78(3), pp.383-390.

Swinburn, Boyd A., Vivica I. Kraak, Steven Allender, Vincent J. Atkins, Phillip I. Baker, Jessica R. Bogard, Hannah Brinsden, et al. 2019. "The Global Syndemic of Obesity, Undernutrition, and Climate Change: The Lancet Commission Report." The Lancet 393 (10173): 791-846.

Taillie, L.S., Reyes, M., Colchero, M.A., Popkin, B. and Corvalán, C., 2020. An evaluation of Chile's Law of Food Labeling and Advertising on sugar-sweetened beverage purchases from 2015 to 2017: A before-and-after study. PLoS medicine, 17(2), p.e1003015.

Temple, N.J., 2018. Fat, sugar, whole grains and heart disease: 50 years of confusion. Nutrients, 10(1), p.39.

The World Health Organization (WHO). 2010. Nutrient profiling: Report of a WHO/IASO technical meeting.

The World Health Organization (WHO). 2011. Nutrient profiling: report of a WHO/IASO technical meeting. Geneva: WHO Department of Nutrition for Health and Development.

The World Health Organization (WHO). 2012. 66/2: Political declaration of the High-level Meeting of the General Assembly on the Prevention and Control of Noncommunicable Disease.

The World Health Organization (WHO). 2014. Policy brief 32: Producing and promoting more food products consistent with a healthy diet.

The World Health Organization (WHO). 2014. Policy brief 34: Reducing the use of salt in the food industry to lower sodium consumption. 
The World Health Organization (WHO). 2017. Roundtable on noncommunicable diseases: Strengthening the role and contribution of the food and non-alcoholic beverage industry to respond to the 2011 Political Declaration of the High-level Meeting of the General Assembly on the Prevention and Control of NCDs.

The World Health Organization (WHO). 2018a. Preparing for the third meeting of the United Nations High-level Meeting on NCDs and strengthening the role and contribution of the private sector.

The World Health Organization (WHO). 2018b. Replace: Trans fat free by 2023. https://www.who.int/nutrition/topics/replace-transfat/

The World Health Organization (WHO). 2019. Five billion people still at risk from industrial trans fat exposure. https://www.who.int/news-room/detail/22-05-2019-five-billionpeople-still-at-risk-from-industrial-trans-fat-exposure

Thow, A.M. and Downs, S., 2016. Fiscal policy options with potential for improving diets for the prevention of noncommunicable diseases (NCDs).

Toews, I., Lohner, S., de Gaudry, D.K., Sommer, H. and Meerpohl, J.J., 2019. Association between intake of non-sugar sweeteners and health outcomes: systematic review and meta-analyses of randomised and non-randomised controlled trials and observational studies. Bmj, 364.

Trieu, K., Neal, B., Hawkes, C., Dunford, E., Campbell, N., Rodriguez-Fernandez, R., Legetic, B., McLaren, L., Barberio, A. and Webster, J., 2015. Salt reduction initiatives around the world-a systematic review of progress towards the global target. PloS one, 10(7), p.e0130247.

van Gunst, A., Roodenburg, A. and Steenhuis, I., 2018. Reformulation as an integrated approach of four disciplines: A qualitative study with food companies. Foods, 7(4), p.64.

van Raaij, J., Hendriksen, M. and Verhagen, H., 2009. Potential for improvement of population diet through reformulation of commonly eaten foods. Public health nutrition, 12(3), pp.325-330.

Vandevijvere, S. and Vanderlee, L., 2019. Effect of Formulation, Labelling, and Taxation Policies on the Nutritional Quality of the Food Supply. Current nutrition reports, 8(3), pp.240-249.

Vlassopoulos, A., Masset, G., Leroy, F. and Spieldenner, J., 2015. Industry approach to nutrition-based product development and reformulation in Asia. Journal of nutritional science and vitaminology, 61(Supplement), pp.S187-S188.

von Philipsborn, P., Stratil, J.M., Heise, T.L., Landgraf, R., Hauner, H. and Rehfuess, E.A., 2018. Voluntary industry initiatives to promote healthy diets: a case study on a major European food retailer. Public health nutrition, 21(18), pp.3469-3476.

Whelton, S.P., Hyre, A.D., Pedersen, B., Yi, Y., Whelton, P.K. and He, J., 2005. Effect of dietary fiber intake on blood pressure: a meta-analysis of randomized, controlled clinical trials. 
Willett, W., Rockström, J., Loken, B., Springmann, M., Lang, T., Vermeulen, S., Garnett, T., Tilman, D., DeClerck, F., Wood, A. and Jonell, M., 2019. Food in the Anthropocene: the EAT-Lancet Commission on healthy diets from sustainable food systems. The Lancet, 393(10170), pp.447-492.

Winkler, J.T., 2013. Nutritional reformulation: Fortification in the factory and in the field. Nutrition and health, 22(1), pp.3-8.

Yeung, C.H.C., Gohil, P., Rangan, A.M., Flood, V.M., Arcot, J., Gill, T.P. and Louie, J.C.Y., 2017. Modelling of the impact of universal added sugar reduction through food reformulation. Scientific reports, 7(1), p.17392. 


\section{ANNEX: EXTENDED EXECUTIVE SUMMARY}

\section{BACKGROUND AND PURPOSE}

Diets are now widely understood to be the biggest single determinant of health in every country. What people are eating is changing rapidly - by historical standards - and clearly influences a wide range of health outcomes. The debate around making diets healthier is far reaching, and the answers are specific to countries, communities, and also to target groups such as mothers, infants, children, and the aged.

In this context, the consumption of processed food is rising everywhere as a significant portion of most people's diets, and the composition of that food is on the agenda of many governments, producers, and consumers alike. Why?

There is growing evidence of the large, detrimental effects of sub-optimal diets on health, including cardiovascular disease, diabetes, and some types of cancers. The deaths and disability-adjusted life years (DALYs) attributed to poor diets, eleven million and 255 million, respectively, have surpassed those from smoking (2017 data; Afshin et al. 2019). High-risk diets are those low in fruits, vegetables, whole grains, legumes, nuts, and seeds and those high in salt, sugar, unhealthy fats, and red and processed meats (Afshin et al. 2019; Willett et al. 2019; Swinburn et al. 2019; Immamura et al. 2015).

Deteriorating nutrition and health outcomes among the global population have stimulated national and international nutrition programmes and policies to strive to reduce the intake of salt, added sugar, and unhealthy fats towards the targets recommended by national governments and the World Health Organization (WHO). Efforts must be ramped up to increase access to and promote the consumption of fresh nutritious foods (such as fruits, vegetables, and whole grains) in line with national dietary guidelines. In parallel, reformulation of processed foods can make an important contribution to shifting diets in the desired direction.

Reformulation is a change to a food or beverage's processing or composition. As a contribution towards nutrition, reformulation can either reduce potentially harmful ingredients or nutrients - such as salt, added sugar, saturated and trans fats, and energy density - or increase potentially beneficial ingredients or nutrients - such as micronutrients, fibre, or protein.

The primary objective of this review; therefore, is to contribute to this debate by surveying the food product reformulation landscape, and to highlight the challenges and opportunities to increasing the effectiveness of food reformulation as one tool that can contribute to improved nutrition. It is important to preface this with several considerations on the scope and approach used in this report.

First, reformulation may be undertaken for a number of reasons unrelated to better public health outcomes via improved nutrition. Companies can and do reformulate products for a variety of other reasons, including to increase nutrient density, improve shelf-life, safety, taste, reduce costs, and improve their competitiveness. It is a good practice, however, to do so in a manner that is neutral or positive with regards to nutritional outcomes. This report, 
however, focusses primarily on reformulation that is undertaken specifically for the purpose of making a positive public health contribution.

Second, the context in which this reformulation to reduce salt, added sugar, and unhealthy fats or to increase nutrient density of foods takes place is very different whether as a voluntary action by a company, or in the context of industry-wide government regulation. The report seeks to distinguish the examples, experience, and good practice within both voluntary and mandatory contexts, including pros and cons of voluntary versus mandatory reformulation. Interestingly, some of the companies that have a commitment to improving their products via reformulation - many of which have made important strides in voluntary contexts - see advantages to mandatory schemes that level the playing field and create the possibility for their efforts to be backed by clearer public health messaging.

Third, we look at some of the complex responses of consumers to the way in which reformulation happens. One recognised downside to reformulation is that it may make consumers feel they can increase consumption of processed foods that have minimal nutritional value, even if reformulation has reduced potentially harmful substances - the so called "licensing effect". Similarly, while reformulation can provide a substantive contribution to nutrient intakes (Friesen et al. 2020), it must be seen as only one small component of a healthy diet.

Finally, in the schema of processed foods, the term 'ultra-processed food' has gained currency since its publication in 2009 and has been used as the basis for some national foodbased dietary guidelines (Monteiro 2009). The use of this term, however, remains controversial — within the food industry particularly, but even to some extent in the nutrition community (Jones 2018; Gibney et al. 2017). This is in part because of the term's presumed pejorative connotation. While the specifics of the definition remain controversial, there is a growing body of evidence that high and regular consumption of ultra-processed foods - at the expense of fresh, diverse foods - has negative implications for weight and health (Hall et al. 2019). This topic continues to be an important part of public research, is central to the policy debate in many countries, regions, and fora and is thus covered in this report.

\section{MAJOR FINDINGS}

Voluntary or Mandatory Reformulation: The food industry may be incentivised to reformulate through labelling, taxes, and nutrient or ingredient limits or bans. Labels can range from front-of-pack labels that include stars, traffic lights, or other symbols to warning labels. Most reformulation has been voluntary. Voluntary reformulation has led to uneven coverage, with some foods being reformulated while others are not, and both still being available on shelves. There have been a few mandatory limits or bans, including for salt and trans fats. Mandatory reformulation allows the public health sector to set meaningful targets and timelines that are based solely on nutrition and health research instead of industry profits and to implement independent monitoring and evaluation, with meaningful consequences for noncompliance. The food industry is also incentivised to reformulate by increasing consumer demands for healthy and sustainable foods. 
Supply and demand challenges to reformulation: On the supply side, it is technically challenging for the food industry to reduce or remove ingredients, especially from highly processed foods. Each ingredient, such as salt or sugar, has several purposes, making it difficult to just remove something or to find an acceptable replacement that maintains the food product's appearance, taste, texture, cost, and shelf-life as well as food safety. Food technology is often a challenge, as the technologies to lower salt, added sugar, and saturated and trans fats may not exist or may be too expensive to be widely used. On the demand side, consumer acceptance of new reformulated products can be unpredictable and risky.

Supply and demand opportunities to reformulate: In the face of public health and climate crises, reformulation allows the food industry to improve the nutrition and sustainability of its food products. The food industry is also being incentivised towards reformulation by several positive incentives, including market demand in response to changing consumer preferences and tastes and the increasing importance of nutrition and health, as well as environmental sustainability, for consumers. Reformulation to remove negative nutrients can be done slowly to avoid losing consumers, and new food products can be made to meet changing consumer demands. This allows food companies to meet demands for healthier and more sustainable products (for which many are willing to pay a premium), including plant-based milks and meat alternatives. Food fortification is considered one of the most cost-effective, proven interventions that is readily available to address vitamin and mineral deficiencies (Copenhagen Consensus 2012; Neufeld et al 2018).

Impact of reformulation on public health: Studies have shown that food reformulation could have significant public health outcomes (Vandevijvere and Vanderlee 2019; Spiteri and Soler 2017; Jaenke et al. 2017). However, it is important to note that it is not possible to discuss causation and that few reformulation programmes have been evaluated in terms of their impact on health outcomes. Evaluating the population impact of specific reformulation initiatives is especially difficult because of the multifactorial and distal nature of chronic diseases to measurement. The health impacts of several reformulation actions have been documented, such as reductions of salt, sugar, and unhealthy fats (Vandevijvere and Vanderlee 2019). Fortification has also been seen as a success story. However, from a public health impact standpoint, some argue that by focusing on just one or a few ingredients to remove, many other highly processed, industrial ingredients are left behind that may also have harmful impacts on health.

\section{RECOMMENDATIONS}

Reformulation can contribute to reducing the dietary intake of salt, sugar, and unhealthy fats via processed foods and provide health benefits. Reformulation also provides an opportunity to add healthy components to foods to improve their nutritional and health profiles. While voluntary reformulation has worked to an extent, mandatory reformulation increases the potential benefits, as it can set more ambitious and comprehensive targets that can be enforced. This should also be done as part of a comprehensive government-led strategy to improve diet quality that should also include mandatory labelling, taxes, and subsidies. 
Reformulation will also not lead to the necessary dietary shift towards more unprocessed and minimally processed foods. To do so, policies and actions are needed that improve the availability, affordability, and demand for all types of nutritious foods, including fruits, vegetables, whole grains, legumes, and some animal-source foods for some nutritionally vulnerable populations. Nonetheless, processed foods, in all of their various forms, are likely to remain a big part of diets in the foreseeable future, and making them contribute more towards the goal of human health is critical. Thus, enhancing the nutritional value of foods, or increasing their nutrient density, and limiting the unhealthful components of certain processed foods through reformulation may have an important role to play in our future food system, but it must be done alongside larger-scale efforts to improve dietary diversity and alleviate poverty.

We would like to thank all those from academe, the public sector, civil society, the UN system, and companies who contributed in an open and frank manner to this report. The goal is to stimulate debate to contribute to the 2021 Nutrition Growth Summit and the 2021 Food System Summit, which will be working to develop food systems that promote healthy diets and nutrition, ensure livelihoods of producers, and are climate and environment-smart. 